\title{
Review Article \\ mTOR Inhibition: From Aging to Autism and Beyond
}

\author{
Matt Kaeberlein \\ Department of Pathology, University of Washington, 1959 NE Pacific Street, D-514, Seattle, WA 98195-7470, USA
}

Correspondence should be addressed to Matt Kaeberlein; kaeber@uw.edu

Received 23 September 2013; Accepted 27 October 2013

Academic Editors: O. Huber, R. Ria, and S.-Y. Shieh

Copyright (C) 2013 Matt Kaeberlein. This is an open access article distributed under the Creative Commons Attribution License, which permits unrestricted use, distribution, and reproduction in any medium, provided the original work is properly cited.

\begin{abstract}
The mechanistic target of rapamycin (mTOR) is a highly conserved protein that regulates growth and proliferation in response to environmental and hormonal cues. Broadly speaking, organisms are constantly faced with the challenge of interpreting their environment and making a decision between "grow or do not grow." mTOR is a major component of the network that makes this decision at the cellular level and, to some extent, the tissue and organismal level as well. Although overly simplistic, this framework can be useful when considering the myriad functions ascribed to mTOR and the pleiotropic phenotypes associated with genetic or pharmacological modulation of mTOR signaling. In this review, I will consider mTOR function in this context and attempt to summarize and interpret the growing body of literature demonstrating interesting and varied effects of mTOR inhibitors. These include robust effects on a multitude of age-related parameters and pathologies, as well as several other processes not obviously linked to aging or age-related disease.
\end{abstract}

\section{Introduction}

mTOR regulates a diverse array of cellular processes through its catalytic function as a serine/threonine protein kinase of the phosphoinositide-3-kinase-related family [1]. It acts within at least two distinct molecular complexes: mTOR complex 1 (mTORC1) and mTOR complex 2 (mTORC2) [2]. The composition of each complex is highly studied, and many of the distinct components of each complex have been characterized $[3,4]$. mTORC1 consists of mTOR, the regulatory-associated protein of mTOR (raptor), the mammalian lethal with Sec13 protein 8 (mLST8), the DEP domain containing mTOR-interacting protein (deptor), and the proline-rich Akt substrate of $40 \mathrm{kDa}$ (PRAS40). mTORC2 also contains mTOR and mLST8, but the remaining mTORC2 components are distinct from mTORCl. These include the rapamycin-insensitive companion of mTOR (rictor), protein observed with rictor (protor), mammalian stress-activated protein kinase-interacting protein $1(\mathrm{mSin} 1)$, and proline-rich protein 5 (PRR5). Both mTOR complexes are essential, as loss of either raptor or rictor results in loss of viability $[5,6]$.

mTOR was first identified from studies in the budding yeast Saccharomyces cerevisiae of mutations that conferred altered sensitivity to the macrolide antibiotic rapamycin (also known as sirolimus) $[7,8]$. Analysis of rapamycin resistant mutants led to the identification of two yeast genes, TOR1 and TOR2, that both encode mTOR kinases. Yeast Torl is found exclusively in mTORC1, while yeast Tor2 functions in both mTOR complexes. Thus, null mutations in yeast TOR1 result in viable but rapamycin-sensitive cells, while null alleles of TOR2 cause loss of viability. Unlike yeast, only a single mTOR-encoding gene has been identified in multicellular eukaryotes, and the resulting mTOR protein functions in both mTORC1 and mTORC2 [9-13].

Of the two mTOR complexes, mTORC1 has been characterized to a much greater extent than mTORC2 and appears to play the more important role in aging and age-related disease. mTORC1 activity induces cell growth and proliferation by promoting mRNA translation and protein synthesis, promoting lipid biogenesis, altering mitochondrial metabolism, repressing autophagy, and modulating gene expression via several transcription factors $[14,15]$. mTORC1 regulates global mRNA translation through at least two distinct and highly conserved substrates: ribosomal S6 kinase (S6K1) and eukaryotic translation initiation factor $4 \mathrm{E}$-binding protein 1 (4E-BP1). Phosphorylation of S6K1 promotes ribosome biogenesis, while phosphorylation of $4 \mathrm{E}-\mathrm{BP} 1$ induces its release from the eukaryotic translation initiation factor $4 \mathrm{E}$ 
(eIF4E), allowing eIF4E to associate with mRNA cap binding proteins and form the cap-dependent translation initiation complex [16].

The mTORC1 complex, in turn, is activated by nutrient and growth cues through sensing of amino acid levels, energy status, and oxygen and in response to hormones and growth factors [15]. Perhaps the most important upstream regulator of $\mathrm{mTORC1}$ is the tuberous sclerosis complex, composed of TSC1 (hamartin) and TSC2 (tuberin). TSC1/2 functions as a GTPase-activating protein for the small Rasrelated GTPase Rheb [17-19]. The mechanism by which Rheb activates TORC1 is not known but requires GTP-bound Rheb and may involve direct physical interaction [20, 21]. TORC1 is also activated by insulin and other growth factors via signaling through phosphatidyl 3-OH kinase and Akt and extracellular-signal-regulated kinase 1/2 (ERK1/2), which are able to phosphorylate and inhibit TSC2 [18, 22, 23]. TORC1 is also regulated via TSC2 by the energy sensing AMPactivated protein kinase (AMPK), which represses mTORC1 when cellular energy status is low by phosphorylating both TSC2 and raptor. [24, 25]. Intracellular amino acids also activate mTORC1, but do so through a TSC1/2-independent manner. Although the details are still being worked out, recent studies have demonstrated that amino acids signal to and activate mTORC1 at the lysosomal surface through a family of four small GTPases termed Rag proteins and a scaffolding complex termed Regulator [26-29]. For a more in-depth description of the regulation and structure of the mTORC1 pathway interested readers are referred to the following detailed reviews [30-33].

Rapamycin, from which mTOR gets its name, was isolated as a compound produced by the bacterium Streptomyces hygroscopicus in soil samples obtained on the island of Rapa Nui [34, 35]. Initially developed as an antifungal compound, it soon became actively studied for its potent antiproliferative and immunomodulatory activities [36, 37]. Although not known at the time it was identified, rapamycin is a specific inhibitor of mTORC1 that acts by binding to the FK506-binding protein $12 \mathrm{kDa}$ (FKBP12), forming a molecular complex that impairs mTORC1 activity $[38,39]$. In general, mTORC1 inhibition by rapamycin results in a reduction in global mRNA translation, altered glucose and lipid metabolism, and increased autophagy [40]. In mammals, rapamycin has broad immunomodulatory and antiinflammatory effects. A plethora of studies have shown that rapamycin treatment results in interesting and varied effects on cellular and organismal physiology, including robust benefits for a variety of pathological conditions (described further below).

Rapamycin derivatives (commonly referred to as rapalogues or rapamycins) were first used clinically to prevent kidney transplant rejection and have since been approved for a few cancers, for use in cardiac eluting stents to prevent restenosis, as well as orphan drug status for tuberous sclerosis and uveitis (Table 1). In addition to these rapamycin derivatives, several new inhibitors of mTOR have been developed that work through an ATP-competitive mechanism or that simultaneously inhibit both PI-3 kinase and mTOR (dual inhibitors). Both of these newer classes of mTOR inhibitors can inhibit both mTORC1 and mTORC2; however, their efficacy in different disease models and clinical trials is still being actively investigated.

\section{2. mTOR Signaling and the Biology of Aging}

Research into the biology of aging has made dramatic progress over the past decade. Once assumed to be an inevitable and immutable process, we now know aging can be modulated genetically, environmentally, and pharmacologically [41, 42]. Multiple single gene mutations have been identified that are sufficient to slow aging and extend lifespan in four of the major model organisms used in biomedical research: the budding yeast Saccharomyces cerevisiae, the nematode Caenorhabditis elegans, the fruit fly Drosophila melanogaster, and the laboratory mouse Mus musculus [4347]. Among these, only a handful of interventions show similar effects on aging in multiple organisms and are, therefore, considered to be conserved modulators of aging. These include dietary restriction and inhibition of mTOR, which extend lifespan in all four species, and reduced insulin/IGF1-like signaling which is associated with increased lifespan in all except yeast [48-50].

The role of the mTOR pathway in aging was first established from studies of aging in budding yeast. Two aging paradigms have been described in yeast: chronological aging, which is defined as the length of time that a yeast cell can survive in a nondividing state, and replicative aging, which is the number of daughter cells a mother cell can produce prior to irreversible cell cycle arrest $[51,52]$. From a screen for stress-resistant, chronologically long-lived mutants, Fabrizio and colleagues isolated a mutation in SCH9 [53], which encodes the yeast homolog of the mTOR substrate ribosomal S6 kinase and is a target of TORC1 in yeast [54]. Subsequent studies went on to show that deletion of either SCH9 or TOR1 (which functions exclusively in yeast mTORCl; see above) is sufficient to extend both replicative and chronological lifespan in budding yeast [55-58].

In parallel with the discoveries that mutations reducing mTORC1 signaling can increase lifespan in yeast, similar results were emerging from genetic studies in both nematodesand fruit flies. In C. elegans, Vellai et al. showed that both genetic depletion and RNAi knockdown of the worm mTOR gene, let-363, resulted in enhanced longevity [59], while Jia et al. found a similar effect from mutations in the raptor gene, daf-15 [60]. Elegant work from the Benzer lab in fruit flies further established this link by examining both upstream and downstream components of the mTORC1 pathway. Lifespan extension was observed following overexpression of Drosophila homologs of TSC1 or TSC2 (negative regulators of mTORC1), as well as dominant negative alleles of Drosophila mTOR or S6 kinase [61].

Following initial demonstrations that inhibition of mTOR could extend lifespan in yeast, worms, and flies, several additional studies replicated these findings (as seen in Components of the mTOR Signaling Pathway That Have Been Manipulated to Increase Lifespan) and provided both genetic and molecular evidence that dietary restriction and 
TABLE 1: Some mTOR inhibitors used clinically and in research.

\begin{tabular}{|c|c|c|c|}
\hline Chemical & Class & Clinical uses/trials & References \\
\hline $\begin{array}{l}\text { Rapamycin } \\
\text { Sirolimus } \\
\text { Rapamune }\end{array}$ & Rapalogue & $\begin{array}{l}\text { FDA approved to prevent organ rejection following renal } \\
\text { transplant and for use in drug eluting stents to prevent } \\
\text { restenosis following angioplasty. Orphan drug status for bone } \\
\text { sarcoma, tuberous sclerosis, and uveitis. Multiple active, } \\
\text { recruiting, and completed trials. }\end{array}$ & {$[35,62,63]$} \\
\hline $\begin{array}{l}\text { Everolimus } \\
\text { RAD001 } \\
\text { Afinitor } \\
\text { Zortress }\end{array}$ & Rapalogue & $\begin{array}{l}\text { FDA approved for subependymal giant cell astrocytoma } \\
\text { (SEGA) associated with tuberous sclerosis, specific forms of } \\
\text { breast and pancreatic cancer, advanced renal cell carcinoma, } \\
\text { noncancerous kidney tumors, and renal and liver transplants. } \\
\text { Multiple active, recruiting, and completed trials. Orphan } \\
\text { drug status for lymphoplasmacytic lymphoma and gastric } \\
\text { cancer. }\end{array}$ & {$[62,63]$} \\
\hline $\begin{array}{l}\text { Temsirolimus } \\
\text { CCI-779 } \\
\text { Torisel }\end{array}$ & Rapalogue & $\begin{array}{l}\text { FDA approved for advanced stage renal cell carcinoma. } \\
\text { Multiple active, recruiting, and completed trials. }\end{array}$ & {$[62,63]$} \\
\hline $\begin{array}{l}\text { Ridaforolimus } \\
\text { AP23573 } \\
\text { MK-8669 } \\
\text { Deforolimus }\end{array}$ & Rapalogue & $\begin{array}{l}\text { Multiple active, recruiting, and completed trials for various } \\
\text { cancers. }\end{array}$ & {$[64]$} \\
\hline $\begin{array}{l}\text { Zotarolimus } \\
\text { ABT-578 }\end{array}$ & Rapalogue & $\begin{array}{l}\text { FDA approved for use in cardiac stents to prevent restenosis } \\
\text { following angioplasty. Multiple active and completed trials. }\end{array}$ & {$[65,66]$} \\
\hline AZD8055 & ATP-competitive mTOR inhibitor & In clinical trials for gliomas, liver cancer, and solid tumors. & {$[67-70]$} \\
\hline AZD2014 & ATP-competitive mTOR inhibitor & $\begin{array}{l}\text { Clinical trials recruiting for metastatic breast and renal } \\
\text { cancers. }\end{array}$ & {$[67]$} \\
\hline OSI-027 & ATP-competitive mTOR inhibitor & $\begin{array}{l}\text { Completed phase } 1 \text { clinical trial in patients with advanced } \\
\text { solid tumors or lymphoma. }\end{array}$ & {$[71,72]$} \\
\hline MLN0128 & ATP-competitive mTOR inhibitor & $\begin{array}{l}\text { Completed and recruiting phase } 1 \text { trials for multiple myeloma } \\
\text { and advanced malignancies. }\end{array}$ & {$[72]$} \\
\hline WYE-132 & ATP-competitive mTOR inhibitor & None. & [73] \\
\hline Torin1 & ATP-competitive mTOR inhibitor & None. & [74] \\
\hline PI-103 & $\mathrm{PI} 3 \mathrm{~K} / \mathrm{mTOR}$ inhibitor & None. & [75] \\
\hline P7170 & $\mathrm{PI} 3 \mathrm{~K} / \mathrm{mTOR}$ inhibitor & $\begin{array}{l}\text { Phase } 1 \text { clinical trial recruiting for advanced refractory solid } \\
\text { tumors. }\end{array}$ & {$[76]$} \\
\hline PF-04691502 & $\mathrm{PI} 3 \mathrm{~K} / \mathrm{mTOR}$ inhibitor & $\begin{array}{l}\text { Phase } 1 \text { trials completed and recruiting; phase } 2 \text { trial for } \\
\text { recurrent endometrial cancer recruiting. }\end{array}$ & {$[77]$} \\
\hline $\begin{array}{l}\text { PF-05212384 } \\
\text { PKI-587 }\end{array}$ & $\mathrm{PI} 3 \mathrm{~K} / \mathrm{mTOR}$ inhibitor & $\begin{array}{l}\text { Phase } 1 \text { clinical trials recruiting for advanced cancers; phase } 2 \\
\text { trial for recurrent endometrial cancer recruiting. }\end{array}$ & {$[78,79]$} \\
\hline GNE477 & PI3K/mTOR inhibitor & None. & \\
\hline PKI-179 & $\mathrm{PI} 3 \mathrm{~K} / \mathrm{mTOR}$ inhibitor & Phase 1 clinical trial terminated. & {$[80]$} \\
\hline WJD008 & $\mathrm{PI} 3 \mathrm{~K} / \mathrm{mTOR}$ inhibitor & None. & \\
\hline $\begin{array}{l}\text { XL765 } \\
\text { SAR245409 }\end{array}$ & $\mathrm{PI} 3 \mathrm{~K} / \mathrm{mTOR}$ inhibitor & $\begin{array}{l}\text { Several phase } 1 \text { trials completed for solid tumors, breast } \\
\text { cancer, malignant gliomas, and recurrent glioblastomas. }\end{array}$ & [81] \\
\hline NVP-BEZ235 & $\mathrm{PI} 3 \mathrm{~K} / \mathrm{mTOR}$ inhibitor & $\begin{array}{l}\text { Multiple phase } 1 \text { trials completed. Phase } 1 / 2 \text { trials active, } \\
\text { ongoing, or recruiting for various cancers. }\end{array}$ & {$[82,83]$} \\
\hline BGT226 & & $\begin{array}{l}\text { Phase } 1 \text { and phase } 1 / 2 \text { trials completed for solid tumors and } \\
\text { breast cancer. }\end{array}$ & {$[84,85]$} \\
\hline SF1126 & & Phase 1 trial completed for solid tumors. & {$[86]$} \\
\hline GSK2126458 & $\mathrm{PI} 3 \mathrm{~K} / \mathrm{mTOR}$ inhibitor & Active and recruiting phase 1 trials for solid tumors. & {$[72,83]$} \\
\hline
\end{tabular}


mTOR modulate aging through overlapping mechanisms. In all three species, dietary restriction is sufficient to reduce mTOR signaling and induce mTOR-dependent changes in metabolism, mRNA translation, and autophagy [87, 88]. In addition, epistasis experiments place mTORC1 and dietary restriction in the same longevity pathway. These data have led to a consensus model that dietary restriction promotes longevity, at least in part, through a reduction in mTORC1 activity $[40,89,90]$.

\section{Components of the mTOR Signaling Pathway That Have Been} Manipulated to Increase Lifespan

mTOR. mTOR is the kinase subunit of mTORC1 and mTORC2. Deletion of budding yeast TOR1 extends both replicative [57, 91] and chronological [58, 92, 93] lifespan. RNAi knockdown of the worm mTOR homolog [59, 9496] and expression of a dominant negative allele of the fly homolog also extends lifespan [61]. Female mice heterozygous for both mTOR and mLST8 are long lived [97]. Mice with two hypomorphic mTOR $(\Delta / \Delta)$ alleles express mTOR at approximately $25 \%$ of wild-type levels and have increased lifespan [98]. Treatment with rapamycin, which disrupts mTORC1, extends both replicative and chronological lifespan in budding yeast $[58,99]$, as well as chronological lifespan of fission yeast [100] when added to the culture medium. Rapamycin also extends lifespan in C. elegans $[101,102]$ and D. melanogaster when provided during adulthood $[103,104]$. Several independent studies have shown lifespan extension in UMHET3 [105-107], 129/Sv [108], and C57BL/6 [109-111] mice.

Raptor. Mutation or RNAi knockdown of the raptor homolog (daf-15) extends lifespan in C. elegans [60].

mLST8. mLST8 is a component of mTORC1. Female mice heterozygous for both mTOR and mLST8 are long-lived [97].

TSC1/TSC2. TSC1 and TSC2 function as upstream negative regulators of mTORC1. Budding yeast and C. elegans do not have homologs of TSC1/2. Overexpression of dTSC1 or dTSC2 extends lifespan in fruit flies [61].

Ribosomal S6 Kinase and 4E-BP. S6 kinase and eukaryotic initiation factor $4 \mathrm{E}$ binding protein (4E-BP) are highly conserved substrates of $\mathrm{mTORC1}$ involved in regulating control of mRNA translation. Deletion of the budding yeast S6 kinase homolog gene SCH9 robustly extends both replicative and chronological lifespan $[53,57]$, and mutation of the fission yeast homolog Sck2 extends chronological lifespan [112]. RNAi knockdown or deletion of the worm S6 kinase homolog rsks-1 extends lifespan in C. elegans $[102,113,114]$. Expression of a dominant negative allele of dS6K [61] or overexpression of 4E-BP [115] extends lifespan in fruit flies. Knockout of the mouse S6K1 gene extends female, but not male, lifespan [116].

Translation Initiation Factors and Ribosomal Proteins. One of the major downstream processes regulated by mTORC1 is mRNA translation $[117,118]$. Mutation or RNAi knockdown of several ribosomal protein genes has been shown to extend lifespan in budding yeast and C. elegans [95, 113, 119-125].

Autophagy. Several reports have suggested that increased autophagy is necessary for lifespan extension in response to mTOR inhibition or dietary restriction, but it has remained unclear whether induction of autophagy is sufficient to extend lifespan [126-128]. A recent study reports that overexpression of the autophagy factor Atg5 activates autophagy and extends lifespan in mice [129].

The evidence that inhibition of mTORC1 is sufficient to extend lifespan in mammals came first from studies performed as part of the National Institute on Aging's Interventions Testing Program (ITP). The ITP is a unique initiative designed to test candidate interventions for effects on lifespan in mice $[130,131]$. Chemical compounds or dietary formulations are nominated through a formal proposal process, selected by a panel of expert scientists and initiated into longevity studies at three independent sites: the University of Michigan, the Jackson Laboratory, and the University of Texas Health Science Center San Antonio. All longevity studies through the ITP are performed in the genetically heterogeneous UMHET3 mouse strain background with treatment beginning at 6 months of age.

Rapamycin was selected for inclusion in the initial ITP cohort, but because of problems associated with developing a stable formulation of the drug in the mouse chow, the animals did not begin receiving rapamycin until about 600 days of age [132]. The rapamycin was delivered in a microencapsulated form suitable for enteric release at a dose of $14 \mathrm{mg} / \mathrm{kg}$ and resulted in a significant lifespan extension of about $15 \%$ in females and $10 \%$ in males [105]. A second ITP study in which the same dose and delivery regimen for rapamycin was initiated at 9 months of age also resulted in a significant lifespan extension in both male and female mice at all three sites; however, the effect was not substantially larger than the prior report of late life administration alone [106]. Several groups have since replicated the ability of rapamycin, as well as genetic inhibition of $\mathrm{mTORC1}$ signaling, to extend lifespan in mice (as seen in Components of the mTOR Signaling Pathway that Have Been Manipulated to Increase Lifespan), making this pathway the current best candidate for interventional strategies to slow aging in mammals $[133,134]$.

2.1. Effects of mTOR on Healthspan and Age-Related Diseases. Healthspan is broadly defined as the period of life spent free of chronic disease and disability. There is growing recognition that, before interventions such as rapamycin can be seriously considered in the context of human aging, we need a better understanding of their impact on overall health during aging $[135,136]$. A major barrier to this, however, is the lack of standardized biomarkers of aging, aging rate, or healthy aging in model systems. For example, although there is broad consensus that rapamycin can extend lifespan in simple eukaryotes and mice, it remains an open and contentious question whether rapamycin is actually slowing the aging process and improving the healthspan of mammals. 
One way to begin to assess whether aging is retarded by rapamycin is through examination of multiple age-related parameters, since the assumption is that an intervention that slows the rate of aging should also slow the onset and progression of multiple age-associated phenotypes [41, 137]. At least three studies have attempted to do this for mice fed the encapsulated rapamycin diet used by the ITP. In general, all three studies found that rapamycin delayed many, but not all, age-sensitive traits $[107,109,110]$. Wilkinson et al. found evidence for improvements in age-sensitive measures of spontaneous activity, liver, heart, endometrial, adrenal, and tendon function but also reported that rapamycin had negative effects on age-associated cataract formation and testicular degeneration [107]. Zhang et al. reported no adverse effects from rapamycin and detected improvements in ageassociated sleep fragmentation (males), gait and rotarod performance decline, and cancer incidence (females) [110]. Of these three studies, Neff et al. performed the most comprehensive analysis of healthspan and identified positive changes from rapamycin in 15 out of 40 parameters quantified [109]. This includes beneficial effects on measures of cardiac function, cancer incidence, cognitive function, tissue pathology, immune system preservation, renal and hepatic function, and muscular and visual performance.

There are several features that complicate and limit aspects of these studies. In particular, negative results cannot be rigorously interpreted in the absence of a positive control, which was lacking in all three cases. Neff et al. misinterpret their failure to detect changes in some of the age-sensitive traits they examined by concluding that rapamycin has no effect on those parameters and, therefore, does not slow aging [109]. This is particularly problematic considering that Neff et al. only examined a single dose of rapamycin $(14 \mathrm{mg} / \mathrm{kg})$. Wilkinson et al. examined three doses of rapamycin in their study $(4.7,14$, and $42 \mathrm{mg} / \mathrm{kg}$ ), but the optimal dose for extending lifespan remains unknown [107]. Neff et al. also noted that many rapamycin sensitive traits were affected similarly in young animals as well as old ones, which they interpreted as an aging-independent effect, but this does not rule out (although it may mask) an aging-dependent effect on the same parameter. Direct comparisons are also of limited utility due to differences in study design, including strain background (UMHET3 in Wilkinson et al. versus C57BL/6 in the other two) and age of intervention onset $(4,13$, or $20-$ 22 months in Neff et al., 9 months in Wilkinson et al., and 19 months in Zhang et al.) and duration.

In addition to the three studies described above, several reports on individual age-sensitive traits have indicated that rapamycin can improve a variety of measures of healthy aging and impact multiple age-related diseases [40]. The mechanisms by which rapamycin impacts so many different age-sensitive processes remains an area of active investigation but most likely involves several different cell-intrinsic and systemic effectors. As mentioned briefly above and reviewed in detail elsewhere $[40,89,138-140]$, regulation of autophagy, mRNA translation, and mitochondrial metabolism almost certainly play central roles in mTOR-mediated effects on disease. In addition, more complex mTOR-mediated effects on gene expression through key transcription factors, as well as interactions with Akt, AMP kinase, p53, and other energy and growth regulatory factors, are likely important [141]. At the systemic level, there is growing evidence that inhibition of mTOR can preserve stem cell function in different tissues [62, 142], decrease cellular senescence [143-145], and generally decrease inflammation $[146,147]$.

2.1.1. Neurodegenerative Diseases and Cognitive Decline. Inhibition of MTORC1 has been studied in several age-related neurodegenerative disease models with striking results [4, 148, 149]. Many of these diseases, including Parkinson's disease, Alzheimer's disease, and Huntington's disease, are associated with the accumulation of aberrant or misfolded proteins. Thus, it has been suggested that defective autophagic degradation is a major component of such diseases [150], and that enhancing autophagy with drugs such as rapamycin could offer a successful therapeutic strategy [151]. With respect to Parkinson's disease, rapamycin has been shown to attenuate dopaminergic neurotoxicity in both fly and mouse models of the disease $[152,153]$. In one recent study, for example, rapamycin showed strong neuroprotective effects in the 1-methyl-4-phenyl-1,2,3,6-tetrahydropyridine (MPTP) mouse model of Parkinson's disease [154]. Similar protective effects have been seen from mTORC1 inhibition in fly, mouse, and human cell culture models of Huntington's disease [155, 156].

Recently, there has been particular interest in the potential utility of mTORC1 inhibitors to treat Alzheimer's disease, the most common form of dementia in people. Alzheimer's disease neuropathology is characterized by the presence of amyloid- $\beta$ protein plaques and neurofibrillary tangles formed of hyperphosphorylated tau and is associated with hyperactivation of mTOR $[157,158]$. In 2010, two independent studies reported positive effects of rapamycin on disease progression in different mouse models of Alzheimer's disease. Majumder et al. [159] found that feeding 3xTg-AD mice a diet supplemented with rapamycin beginning at 2 months of age caused a significant reduction in plaques, tangles, and cognitive defects. Interestingly, no benefit was seen when the same therapy was initiated at 15 months of age, suggesting that the protective effects of $\mathrm{mTORC1}$ inhibition are required early in this disease model. Spilman et al. [160] showed similar beneficial effects from rapamycin in the PDAPP transgenic mouse model of Alzheimer's disease. Rapamycin has also been shown to prevent disease progression in human (h)APP mice when treatment is initiated prior to disease onset and to improve cerebral blood flow and cognitive function even when administered after disease onset [161].

The growing evidence of a positive benefit from mTOR inhibition in neurodegenerative diseases raises the question of whether similar benefits might have also been observed for age-related declines in cognitive function in the absence of frank neurological disease. Prior studies had provided mixed evidence for such effects. Acute mTORC1 inhibition can have a negative effect on long-term plasticity required for memory, which is thought to result from inhibition of mRNA translation required for long-term synaptic changes; however, hyperactivation of mTOR in mammals also causes 
defects in plasticity and memory [162]. Recent studies assessing the effects of chronic mTORC1 inhibition on cognitive function during normal aging in mice have generally found evidence for protection against cognitive decline, particularly on tasks measuring exploratory activity and spatial learning and memory $[109,163,164]$. Intriguingly, there are also indications that rapamycin enhances cognitive function in young mice and has antianxiety and antidepressive effects at all ages tested $[163,165]$.

2.1.2. Cancer. A majority of tumors show evidence for activation of mTOR signaling, and mTOR inhibition has been studied extensively as a potential therapy for a wide variety of cancers [166-168]. Rapamycin and rapamycin derivatives potently inhibit growth of solid tumor cell lines, and rapamycin has been shown to enhance survival and reduce tumor burden in several cancer-prone mouse models, including heterozygous p53+/- [169], heterozygous Rb +/mice [170], and multiple tumor xenograft models [171-176]. The effects of rapamycin on total cancer incidence in mice during aging are less clear. The ITP studies where rapamycin is provided in the diet throughout life have not resulted in substantial changes in tumor frequency at time of death, although since the animals live longer this suggests a delay in tumor formation and/or progression $[105,107]$

Despite the robust and nearly universal anticancer effects in animal and cell culture models, rapamycin derivatives have shown disappointing efficacy in several clinical trials, with the exception of renal cell carcinoma and a few other rare forms of cancer $[166,177]$. Numerous trials are underway using mTOR inhibitors against different tumor types, and their use in neuroendocrine tumors of the pancreas and intestine, mantle cell lymphoma, and sarcomas appears to be particularly promising [178]. It is believed that the lack of potent efficacy by rapamycin in cancer patients may result from activation of Akt signaling following chronic mTOR inhibition. Initial studies of dual PI3K/mTOR inhibitors and combination therapies aimed at simultaneously targeting both mTOR and Akt have provided promising results (see Table 1).

2.1.3. Cardiac Function. Several recent studies have suggested that aberrant activation of mTOR underlies a variety of pathological conditions in the heart, both as a consequence of normal aging, as well as damage that may result from non-age-related trauma. The most direct evidence that inhibition of mTOR can retard age-related changes in heart function comes from a study in which 24-month-old C57BL/6 mice were treated with rapamycin for 3 months [179]. After this treatment regimen, cardiac function was dramatically improved, as assessed through a variety of measures including ultrasound imaging, gene expression profiling, echocardiography, and cytokine profiling to assess cardiac inflammation. Notably, skeletal muscle function and spontaneous activity were also improved in this study [179]. Treatment with rapamycin also inhibits angiotensin II induced increases in protein synthesis in cardiac myocytes [180], and evidence has accumulated that MTORC1 inhibition may be generally protective against cardiomyopathy. The first evidence that rapamycin may prove beneficial in this context was provided by studies using a pressure overload model in mice where rapamycin significantly reduced cardiac hypertrophy when administered either before or after the surgery [181, 182]. Since then, rapamycin and rapamycin derivatives have been reported to provide beneficial effects in numerous models of cardiomyopathy, including hormoneinduced cardiomyopathy [183], cardiac ischemia/reperfusion injury $[184,185]$, hypertrophic cardiomyopathy in a mouse model of LEOPARD syndrome [186], and in rat, mouse, and zebrafish models of dilated cardiomyopathy [187-191].

2.1.4. Diabetes and Obesity. The relationship between mTOR signaling and age-related metabolic disorders is less straightforward than for other age-related phenotypes. In rodents and people, aging is associated with an increase in adiposity, increased insulin resistance, and reduced ability to maintain glucose homeostasis $[192,193]$. Data from both animal models and clinical studies suggest that inhibition of mTOR can result in either reduced or improved metabolic homeostasis, depending on context and the assays used. The situation is further complicated by the fact that obesity itself can result in chronic activation of mTOR, which has been linked to obesity-associated cancer, beta cell adaptation preceding type II diabetes, nonalcoholic fatty liver diseases, and other complications $[165,194,195]$.

In genetic mouse models, absence of either mTORC1 specifically in adipose or S6k1 in the whole body is sufficient to prevent diet-induced obesity [196-198]. The S6k1 knockout mice are also hypoinsulinaemic and glucose intolerant, however, due to a decrease in beta cell size and function [196]. This is consistent with reports that rapamycin treatment can also impair beta cell function in both animals models and human patients [199]. Mice chronically treated with rapamycin develop glucose intolerance and insulin resistance, which has recently been attributed to inhibition of mTORC2 [97], and dyslipidemia is a side effect associated with rapamycin derivatives in people. Despite these diabeteslike symptoms, both S6k1 knockout mice and rapamycin treated mice are long-lived, suggesting that if the metabolic effects are detrimental to health, they are not so detrimental as to limit survival, at least in mice. One recent study looked directly at effects of rapamycin on obesity using the $\mathrm{db} / \mathrm{db}$ mouse model of diabetic dyslipidemia [200]. Animals were fed either a normal diet or encapsulated rapamycin in the diet for 6 months starting at 2 months of age. At the end of the trial period, rapamycin-treated animals had lower body weight, lower percent body fat, increased insulin sensitivity, and increased markers of beta oxidation and mitochondrial biogenesis. It has also been pointed out that the "starvation induced diabetes" associated with mTORC1 inhibition differs substantially from type II diabetes, which is caused by insulin resistance resulting from overnutrition and is associated with mTOR activation [201]. Thus, additional study is needed to determine whether targeted inhibition of mTORC1 can prove useful against type II diabetes or obesity and whether the potential changes in lipid profile, insulin sensitivity, 
and glucose homeostasis resulting from chronic mTORC1 inhibition represent a significant health risk.

2.1.5. Immune Function. The primary clinical use of rapamycin derivatives is in combination therapy to depress immune function in order to prevent organ transplant rejection. Thus, it is somewhat surprising that, in the context of aging, there is evidence that rapamycin may preserve immune function. As in people, old mice show a reduced capacity to mount an immune response to influenza vaccination. Treating 22-24-month-old mice with rapamycin for only 6 weeks doubled the percentage and number of $\mathrm{B}$ (but not $\mathrm{T}$ ) cells in the bone marrow and restored the capacity of the aged animals' immune system to mount an effective response to influenza vaccination that was protective against subsequent infection [111]. This is consistent with reports that rapamycin derivatives can enhance immune system efficacy in multiple settings, including tuberculosis [202] and antitumor vaccine [203] responses in mice and vaccinia vaccination in nonhuman primates [204]. The apparent contradiction between these observations and the perception that rapamycin is a general immunosuppressant may be explained by observations that mTOR can exert divergent immunoregulatory functions during immune cell activation and differentiation depending on the cell subset type. Thus, the notion that rapamycin is a potent and general immunosuppressant is clearly overly simplistic, with the actual outcome likely depending on dose and duration of treatment, immune cell type, and specific immune challenge.

2.1.6. Kidney Disease. Chronic kidney disease affects more than $45 \%$ of people over age 70 and likely contributes to a decline in function of multiple organ systems $[205,206]$. Rapamycins are used clinically to reduce nephrotoxicity, to prevent allograft rejection, and as a treatment for renal cell carcinoma [207]. Activation of mTOR signaling is also associated with several common forms of kidney disease, suggesting that inhibition of mTOR might have broader therapeutic benefits for kidney health. Consistent with this, rapamycins have been shown to reduce kidney fibrosis, attenuate diabetic nephropathy, and improve outcome in animal models of polycystic kidney disease (discussed further below).

2.1.7. Age-Related Macular Degeneration. Age-related macular degeneration is the leading cause of blindness in Western countries [208]. A contributing cause is capillary overgrowth in the choroid layer of the eye, which has been attributed to excessive production of VEGF. Rapamycin has been shown to reduce VEGF expression in retinal pigment epithelium and inhibit angiogenesis in vitro [209]. In a rat model of age-related macular degeneration, rapamycin decreased the incidence and severity of retinopathy [210], and in human patients rapamycin appeared to decrease the need for antiVEGF intravitreal injections by approximately half [211].

2.1.8. Progeria. Hutchinson-Gilford progeria syndrome is a rare autosomal genetic disease in which a subset of tissues appear to undergo accelerated aging [212]. Patients seem normal at birth but develop a childhood progeroid phenotype and suffer death in the early teens. Hutchinson-Gilford progeria syndrome is most typically caused by a de novo mutation in the lamin $\mathrm{A} / \mathrm{C}$ gene (LMNA) that activates a cryptic splice site, producing an abnormal lamin A protein termed progerin. Accumulation of progerin leads to aberrant nuclear morphology in vitro and is believed to directly cause the disease phenotypes. It was recently reported that treatment of cells from Hutchinson-Gilford progeria syndrome patients with rapamycin corrected the nuclear morphology defect, delayed the onset of cellular senescence, and enhanced the clearance of progerin through autophagic degradation [213]. There is currently no effective treatment for HutchinsonGilford progeria syndrome, and these data provide hope that rapamycin derivatives or other mTOR inhibitors might slow disease progression in Hutchinson-Gilford progeria syndrome patients [214].

\section{Pathological Consequences of Aberrant Activation of $\mathbf{m T O R}$ and Disease Suppression by Rapamycin}

In addition to its role in aging and age-related diseases, mTOR has also been associated with a growing list of diseases not clearly associated with aging. In many of these cases, the disease state is correlated with (and in some has been shown causally related to) aberrant activation of mTOR signaling. In such cases, pharmacological inhibition of mTOR may be therapeutic, by reducing mTOR activity to normal levels.

\subsection{Tuberous Sclerosis Complex and mTOR-Related Neuroge-} netic Disorders. The first human disease definitively linked to aberrant mTOR activation is tuberous sclerosis complex, a rare genetic disease characterized by nonmalignant tumors of the brain, kidneys, heart, lungs, eyes, and skin [215]. Tuberous sclerosis complex is inherited in an autosomal dominant fashion and occurs in about 1:6000 live births [216]. About $85 \%$ of cases of tuberous sclerosis complex are caused by loss of function mutations in either TSC1 or TSC2, resulting in hyperactivation of $\mathrm{mTORC1}$ in affected tissues [217]. In addition to tumor development, epilepsy is commonly associated with tuberous sclerosis complex (see below) and about 50\% of patients have some form of a learning disorder, including autistic behaviors (also see below) [218-220]. Most of the neurological symptoms associated with tuberous sclerosis complex are thought to be due to the formation of cortical tubers, which form at the gray-white matter junction.

Inhibition of mTOR with rapamycin has been shown to reduce or prevent adverse consequences of TSC1 or TSC2 mutation in a variety of cell culture and animal models $[221,222]$. Treatment with rapamycin or temsirolimus in a neuronal TSC1 knockout mouse, for example, dramatically improved survival and suppressed behavioral and brain pathological defects associated with the disease, including complete suppression of seizures [223]. In another study of Tsc2 +/- heterozygous mice, rapamycin treatment reduced kidney tumors by more than $90 \%$ [224]. Initial data from 
clinical trials indicates that mTOR inhibitors can positively impact several tuberous sclerosis manifestations [225-230] and, according to the Clinicaltrials.gov database, more than a dozen clinical trials are ongoing for assessing therapeutic effects of mTOR inhibitors in tuberous sclerosis complex. To date, everolimus is the only mTOR inhibitor clinically approved for treatment of tuberous sclerosis.

In addition to tuberous sclerosis complex, at least three other neurogenetic disorders have been associated with aberrant activation of mTOR in the brain: neurofibromatosis 1, fragile X syndrome, and PTEN associated conditions [231]. Although each has distinct etiology, these conditions share several overlapping phenotypes with tuberous sclerosis complex, including an increased likelihood of impaired cognitive function, autism spectrum disorder, epilepsy and seizures, cutaneous lesions, and tumors.

3.2. Epilepsy. Epilepsy is a neurological disorder that affects up to $1 \%$ of the population and is characterized by recurrent seizures [232]. As described above, it is clear that aberrant mTOR signaling contributes to epilepsy associated with tuberous sclerosis complex. This raises the intriguing possibility that hyperactivation of mTOR may also underlie or contribute to epileptogenesis in other contexts and, by extension, inhibitors of mTOR may prove therapeutic in this context [221, 233]. Consistent with this idea, epileptic seizures are also associated with neuronal ablation of the tumor suppressor gene phosphatase and tensin homolog deleted on chromosome ten (PTEN), which acts indirectly as a negative regulator of mTOR, and both temsirolimus and rapamycin have been shown to reduce seizures in these animals [234]. Rapamycin has also been shown to reduce or prevent seizures and epilepsy development in several animal models of acquired epilepsy, including kainic acid and pilocarpine-induced status epilepticus. Aberrant mTOR activation has also been associated with some forms of focal cortical dysplasia, a malformation of brain development that is among the most common forms of pediatric epilepsy [235]. There is some evidence that rapamycin may not be effective for all forms of epilepsy; for example, no effect was detected in a mouse model of pilocarpine induced temporal lobe epilepsy [236], although negative results in such studies are difficult to interpret (discussed further below). Clinical trials are ongoing to further examine the effects of everolimus on epilepsy associated with tuberous sclerosis complex.

3.3. Autism. As with epilepsy, the link between aberrant mTOR activation and autism is strongest in tuberous sclerosis complex; between 20 and 60\% of tuberous sclerosis patients are diagnosed with autism $[219,237]$, which may account for $1-4 \%$ of all autism cases [238]. In addition to tuberous sclerosis, however, there is growing evidence that dysregulated mTOR activity may contribute to a wider variety of autism spectrum disorders. As with epilepsy, mutations in PTEN that lead to aberrant activation of mTOR are associated with autism [239]. In addition, mutations in the downstream mTOR target eukaryotic translation initiation factor $4 \mathrm{E}$ (eIF4E) have also been associated with autism
[240]. There is also evidence for a strong association between macrocephaly (large head size) early in life and autism spectrum disorders, as well as genetic diseases linked to autism and mTOR hyperactivation, including tuberous sclerosis complex, neurofibromatosis type I, Lhermitte-Duclos syndrome, and Fragile X syndrome [241]. Taken together these data suggest that disinhibited mTOR may cause, or at least contribute to, many cases of autism spectrum disorder. Clinical trials are ongoing to assess whether everolimus can reduce autistic symptoms in tuberous sclerosis patients.

3.4. Polycystic Kidney Disease. Autosomal dominant polycystic kidney disease is an inherited disorder most often caused by mutations in the PKD1, which encodes the polycystin1 protein [242]. In the normal adult kidney, mTOR is low; however, it becomes activated in response to damage or insults that require cell proliferation within the kidney [243]. In autosomal dominant polycystic kidney disease, mTOR is constitutively hyperactivated, leading to inappropriate proliferation and the formation of thousands of cysts within the kidneys. The molecular mechanism for this aberrant activation of mTOR has begun to be understood, with the discovery that polycystin-1 can indirectly regulate mTOR activity in the kidney through a physical interaction with tuberin, which is encoded by the TSC2 gene [244]. In human patients with autosomal dominant polycystic kidney disease, there is evidence of mTOR hyperactivation in renal cells lining the cysts, and rapamycin has been shown to delay progression in mouse models of the disease [244]. Sirolimus is also used clinically in some autosomal dominant polycystic kidney disease patients following kidney transplant, in order to prevent organ rejection [245]. In some such patients, the polycystic kidneys are left in place. In one study, a reduction in kidney volume of these polycystic kidneys was observed, relative to similar transplant patients that did not receive sirolimus [244]. The clinical efficacy of mTOR inhibitors for autosomal dominant polycystic kidney disease is still under investigation with several ongoing clinical trials. Completed clinical trials have shown mixed results, perhaps due to differences in dosing, size, and duration of treatment [246248].

3.5. Chronic Pain and Traumatic Injury. Two additional pathological conditions where mTOR has been implicated are chronic pain and traumatic injury. The relationship between mTOR and chronic pain is thought to derive from mTORregulated mRNA translation in the nociceptor, a sensory neuron that sends pain signals to the spinal cord and brain [249]. Rapamycin has been shown to reduce chronic and neuropathic pain in multiple rat and mouse models [250254]. In rodent models of traumatic cardiac and brain injury, rapamycin has also been shown to improve outcome [255260]. Both chronic pain and traumatic injury are highly clinically relevant, and it will be of interest to see whether mTOR inhibition has similar effects on these conditions in people. 


\section{Considerations and Future Directions}

Given all the negative consequences associated with activation of mTOR and the apparent benefits associated with inhibiting mTOR (slower aging, less disease, better brain function, and less pain-at least in animal models), it is tempting to consider the potential benefits associated with widespread use of mTOR inhibitors. Of course, many of the beneficial effects associated with mTOR inhibition have only been seen in preclinical models, and it remains unclear whether similar effects will be seen in people in most cases. Clinical trials with mTOR inhibitors have been mixed, with robust benefits being observed in some cases and minimal, if any, benefits in others. Nonetheless, although definitive proof is lacking, it seems likely that a broad range of agedependent diseases and disorders would be reduced in people if appropriate regulation of mTOR could be achieved.

Before this can happen, however, several hurdles must be overcome. One of the most important is a better understanding of the adverse consequences of chronic mTOR inhibition. In mice, chronic inhibition of mTORC1 with rapamycin is associated with insulin resistance and hyperlipidemia [97], but the mice are healthier and have longer lifespans, suggesting that (at least for mice) this altered metabolic state is not pathological. Side effects associated with the clinically used mTOR inhibitors include increased risks of stomatitis (mouth ulcers), diarrhea and nausea, hyperlipidemia, and infection (presumably due to immune suppression). As mentioned above, there is also evidence for enhanced cataract formation and male sterility in mice receiving lifelong rapamycin, although it is unclear whether these effects would also occur in people.

Appropriate dosing of mTOR inhibitors is also a major challenge that needs to be addressed before it is possible to assess their broad efficacy in both preclinical and clinical models. Even limiting the consideration to rodent studies of rapamycin, a wide range of doses and treatment regimens have been employed across the spectrum of phenotypes examined. Rarely is a dose response profile ever performed in these types of studies, and in cases where negative results have been obtained it is unclear whether this is because mTOR inhibition is ineffective or because of suboptimal dosing. The studies examining effects of rapamycin on longevity and healthspan are a good example of this. The majority of studies in this area have used a single dose and delivery protocol: $14 \mathrm{mg} / \mathrm{kg} /$ day in the diet in the form of encapsulated rapamycin. Will higher doses of rapamycin have a greater or lesser effect on lifespan and healthspan? How does delivery of encapsulated rapamycin compare to intraperitoneal injection or other forms of delivery in terms of biological activity? These are critical questions that need to be answered before we can even begin to assess the likely translational potential of these findings.

Another important area of future investigation will be the similarities and differences between different classes and types of mTOR inhibitors, both alone and in combination with other drugs. As shown in Table 1, there are three different classes of mTOR inhibitors either already in clinical use or currently being evaluated in clinical trials. Rapamycin derivatives have been the most studied and, with respect to aging, rapamycin is the only mTOR inhibitor examined thus far. It remains to be seen whether more or less potent effects on longevity and healthspan will be seen with mTOR inhibitors that target both mTORC1 and mTORC2 and, in the case of the dual kinase inhibitors, also target PI3K. Likewise, combinatorial effects of inhibiting mTOR along with other putative aging-related factors such as AMP kinase and sirtuins may prove even more effective at enhancing healthy aging than rapamycin alone.

\section{Conclusion}

Given the breadth of pathological conditions where mTOR has already been implicated, it seems likely that additional therapeutic uses for mTOR inhibitors will be discovered in the near future. While potential negative effects of mTOR inhibition need to be addressed, they appear generally manageable and, as new mTOR inhibitors continue to be developed, it may be possible to maximize the beneficial effects of targeted mTOR inhibition while reducing adverse effects.

\section{Conflict of Interests}

Matt Kaeberlein has a patent entitled "Identification of aging genes through large-scale analysis" (United States Patent 7622271) that has been licensed by GenetikSignal, Inc., for use in the identification of natural product mTOR inhibitors.

\section{References}

[1] C. T. Keith and S. L. Schreiber, "PIK-related kinases: DNA repair, recombination, and cell cycle checkpoints," Science, vol. 270, no. 5233, pp. 50-51, 1995.

[2] R. Loewith, E. Jacinto, S. Wullschleger et al., "Two TOR complexes, only one of which is rapamycin sensitive, have distinct roles in cell growth control," Molecular Cell, vol. 10, no. 3, pp. 457-468, 2002.

[3] H. Zhou and S. Huang, "The complexes of mammalian target of rapamycin," Current Protein and Peptide Science, vol. 11, no. 6, pp. 409-424, 2010.

[4] I. Bracho-Valdés, P. Moreno-Alvarez, I. Valencia-Martínez, E. Robles-Molina, L. Chávez-Vargas, and J. Vázquez-Prado, "MTORC1- and mTORC2-interacting proteins keep their multifunctional partners focused," IUBMB Life, vol. 63, no. 10, pp. 880-898, 2011.

[5] D. A. Guertin, D. M. Stevens, C. C. Thoreen et al., "Ablation in mice of the mTORC components raptor, rictor, or mLST8 reveals that mTORC2 is required for signaling to Akt-FOXO and PKCalpha, but not S6K1," Developmental Cell, vol. 11, no. 6, pp. 859-871, 2006.

[6] S. B. Helliwell, I. Howald, N. Barbet, and M. N. Hall, “TOR2 is part of two related signaling pathways coordinating cell growth in Saccharomyces cerevisiae," Genetics, vol. 148, no. 1, pp. 99-112, 1998.

[7] J. Heitman, N. R. Movva, and M. N. Hall, "Targets for cell cycle arrest by the immunosuppressant rapamycin in yeast," Science, vol. 253, no. 5022, pp. 905-909, 1991. 
[8] R. Cafferkey, P. R. Young, M. M. McLaughlin et al., "Dominant missense mutations in a novel yeast protein related to mammalian phosphatidylinositol 3-kinase and VPS34 abrogate rapamycin cytotoxicity," Molecular and Cellular Biology, vol. 13, no. 10, pp. 6012-6023, 1993.

[9] C. J. Sabers, M. M. Martin, G. J. Brunn et al., "Isolation of a protein target of the FKBP12-rapamycin complex in mammalian cells," Journal of Biological Chemistry, vol. 270, no. 2, pp. 815822, 1995.

[10] E. J. Brown, M. W. Albers, T. B. S. Tae Bum Shin et al., "A mammalian protein targeted by G1-arresting rapamycinreceptor complex," Nature, vol. 369, no. 6483, pp. 756-758, 1994.

[11] M. I. Chiu, H. Katz, and V. Berlin, "RAPT1, a mammalian homolog of yeast Tor, interacts with the FKBP12/rapamycin complex," Proceedings of the National Academy of Sciences of the United States of America, vol. 91, no. 26, pp. 12574-12578, 1994.

[12] D. M. Sabatini, H. Erdjument-Bromage, M. Lui, P. Tempst, and S. H. Snyder, "RAFT1: a mammalian protein that binds to FKBP12 in a rapamycin-dependent fashion and is homologous to yeast TORs," Cell, vol. 78, no. 1, pp. 35-43, 1994.

[13] Y. Chen, H. Chen, A. E. Rhoad et al., "A putative sirolimus (rapamycin) effector protein," Biochemical and Biophysical Research Communications, vol. 203, no. 1, pp. 1-7, 1994.

[14] M. Laplante and D. M. Sabatini, "Regulation of mTORC1 and its impact on gene expression at a glance," Journal of Cell Science, vol. 126, pp. 1713-1719, 2013.

[15] M. Laplante and D. M. Sabatini, "mTOR signaling at a glance," Journal of Cell Science, vol. 122, no. 20, pp. 3589-3594, 2009.

[16] X. M. Ma and J. Blenis, "Molecular mechanisms of mTORmediated translational control," Nature Reviews Molecular Cell Biology, vol. 10, no. 5, pp. 307-318, 2009.

[17] K. Inoki, Y. Li, T. Xu, and K.-L. Guan, "Rheb GTpase is a direct target of TSC2 GAP activity and regulates mTOR signaling," Genes and Development, vol. 17, no. 15, pp. 1829-1834, 2003.

[18] K. Inoki, Y. Li, T. Zhu, J. Wu, and K.-L. Guan, "TSC2 is phosphorylated and inhibited by Akt and suppresses mTOR signalling," Nature Cell Biology, vol. 4, no. 9, pp. 648-657, 2002.

[19] B. D. Manning, A. R. Tee, M. N. Logsdon, J. Blenis, and L. C. Cantley, "Identification of the tuberous sclerosis complex-2 tumor suppressor gene product tuberin as a target of the phosphoinositide 3-kinase/Akt pathway," Molecular Cell, vol.10, no. 1, pp. 151-162, 2002.

[20] X. Long, F. Müller, and J. Avruch, "TOR action in mammalian cells and in Caenorhabditis elegans," Current Topics in Microbiology and Immunology, vol. 279, pp. 115-138, 2003.

[21] X. Long, C. Spycher, Z. S. Han, A. M. Rose, F. Müller, and J. Avruch, "TOR deficiency in C. elegans causes developmental arrest and intestinal atrophy by inhibition of mRNA translation," Current Biology, vol. 12, no. 17, pp. 1448-1461, 2002.

[22] C. J. Potter, L. G. Pedraza, and T. Xu, "Akt regulates growth by directly phosphorylating Tsc2," Nature Cell Biology, vol. 4, no. 9, pp. 658-665, 2002.

[23] L. Ma, Z. Chen, H. Erdjument-Bromage, P. Tempst, and P. P. Pandolfi, "Phosphorylation and functional inactivation of TSC2 by Erk: implications for tuberous sclerosis and cancer pathogenesis," Cell, vol. 121, no. 2, pp. 179-193, 2005.

[24] K. Inoki, T. Zhu, and K.-L. Guan, "TSC2 mediates cellular energy response to control cell growth and survival," Cell, vol. 115, no. 5, pp. 577-590, 2003.

[25] D. M. Gwinn, D. B. Shackelford, D. F. Egan et al., "AMPK phosphorylation of raptor mediates a metabolic checkpoint," Molecular Cell, vol. 30, no. 2, pp. 214-226, 2008.
[26] Y. Sancak, T. R. Peterson, Y. D. Shaul et al., "The rag GTPases bind raptor and mediate amino acid signaling to mTORC1," Science, vol. 320, no. 5882, pp. 1496-1501, 2008.

[27] Y. Sancak, L. Bar-Peled, R. Zoncu, A. L. Markhard, S. Nada, and D. M. Sabatini, "Ragulator-rag complex targets mTORC1 to the lysosomal surface and is necessary for its activation by amino acids," Cell, vol. 141, no. 2, pp. 290-303, 2010.

[28] R. Zoncu, L. Bar-Peled, A. Efeyan, S. Wang, Y. Sancak, and D. M. Sabatini, "mTORC1 senses lysosomal amino acids through an inside-out mechanism that requires the vacuolar $\mathrm{H}^{+}$-ATPase," Science, vol. 334, no. 6056, pp. 678-683, 2011.

[29] E. Kim, P. Goraksha-Hicks, L. Li, T. P. Neufeld, and K.-L. Guan, "Regulation of TORC1 by Rag GTPases in nutrient response," Nature Cell Biology, vol. 10, no. 8, pp. 935-945, 2008.

[30] M. Laplante and D. M. Sabatini, "mTOR signaling," Cold Spring Harbor Perspectives in Biology, vol. 4, 2012.

[31] M. Laplante and D. M. Sabatini, "mTOR signaling in growth control and disease," Cell, vol. 149, no. 2, pp. 274-293, 2012.

[32] S. G. Kim, G. R. Buel, and J. Blenis, "Nutrient regulation of the mTOR complex 1 signaling pathway," Molecules and Cells, vol. 35, pp. 463-473, 2013.

[33] D. E. Martin and M. N. Hall, "The expanding TOR signaling network," Current Opinion in Cell Biology, vol. 17, no. 2, pp. 158166, 2005.

[34] S. N. Sehgal, H. Baker, and C. Vezina, "Rapamycin (AY 22,989), a new antifungal antibiotic-II. Fermentation, isolation and characterization," Journal of Antibiotics, vol. 28, no. 10, pp. 727732, 1975.

[35] C. Vezina, A. Kudelski, and S. N. Sehgal, "Rapamycin (AY 22, 989), a new antifungal antibiotic-I. Taxonomy of the producing streptomycete and isolation of the active principle," Journal of Antibiotics, vol. 28, no. 10, pp. 721-726, 1975.

[36] J. Douros and M. Suffness, "New antitumor substances of natural origin," Cancer Treatment Reviews, vol. 8, no. 1, pp. 63-87, 1981.

[37] C. P. Eng, S. N. Sehgal, and C. Vezina, "Activity of rapamycin (AY-22,989) against transplanted tumors," Journal of Antibiotics, vol. 37, no. 10, pp. 1231-1237, 1984.

[38] J. Chen, X.-F. Zheng, E. J. Brown, and S. L. Schreiber, "Identification of an 11-kDa FKBP12-rapamycin-binding domain within the 289-kDa FKBP12-rapamycin-associated protein and characterization of a critical serine residue," Proceedings of the National Academy of Sciences of the United States of America, vol. 92, no. 11, pp. 4947-4951, 1995.

[39] J. Choi, J. Chen, S. L. Schreiber, and J. Clardy, "Structure of the FKBP12-rapamycin complex interacting with the binding domain of human FRAP," Science, vol. 273, no. 5272, pp. 239242, 1996.

[40] S. C. Johnson, P. S. Rabinovitch, and M. Kaeberlein, "mTOR is a key modulator of ageing and age-related disease," Nature, vol. 493, pp. 338-345, 2013.

[41] M. Kaeberlein, “Longevity and aging," F1000prime Reports, vol. 5, p. 5, 2013.

[42] G. M. Martin, "The biology of aging: 1985-2010 and beyond," FASEB Journal, vol. 25, no. 11, pp. 3756-3762, 2011.

[43] M. Kaeberlein, "Lessons on longevity from budding yeast," Nature, vol. 464, no. 7288, pp. 513-519, 2010.

[44] M. E. Yanos, C. F. Bennett, and M. Kaeberlein, "Genome-wide RNAi longevity screens in Caenorhabditis elegans," Current Genomics, vol. 13, pp. 508-518, 2012. 
[45] T. E. Johnson, "25 years after age-1: genes, interventions and the revolution in aging research," Experimental Gerontology, vol. 48, p. 640, 2013.

[46] A. Bartke, "Single-gene mutations and healthy ageing in mammals," Philosophical Transactions of the Royal Society B, vol. 366, p. 28, 2011.

[47] L. Partridge, "Some highlights of research on aging with invertebrates, 2010," Aging Cell, vol. 10, no. 1, pp. 5-9, 2011.

[48] L. Fontana, L. Partridge, and V. D. Longo, "Extending healthy life span-from yeast to humans," Science, vol. 328, no. 5976, pp. 321-326, 2010.

[49] C. J. Kenyon, “The genetics of ageing," Nature, vol. 464, no. 7288, pp. 504-512, 2010.

[50] B. K. Kennedy, K. K. Steffen, and M. Kaeberlein, "Ruminations on dietary restriction and aging," Cellular and Molecular Life Sciences, vol. 64, no. 11, pp. 1323-1328, 2007.

[51] V. D. Longo, G. S. Shadel, M. Kaeberlein, and B. Kennedy, "Replicative and chronological aging in Saccharomyces cerevisiae," Cell Metabolism, vol. 16, p. 18, 2012.

[52] K. A. Steinkraus, M. Kaeberlein, and B. K. Kennedy, "Replicative aging in yeast: the means to the end," Annual Review of Cell and Developmental Biology, vol. 24, pp. 29-54, 2008.

[53] P. Fabrizio, F. Pozza, S. D. Pletcher, C. M. Gendron, and V. D. Longo, "Regulation of longevity and stress resistance by Sch9 in yeast," Science, vol. 292, no. 5515, pp. 288-290, 2001.

[54] J. Urban, A. Soulard, A. Huber et al., "Sch9 is a major target of TORC1 in Saccharomyces cerevisiae," Molecular Cell, vol. 26, no. 5, pp. 663-674, 2007.

[55] P. Fabrizio, L.-L. Liou, V. N. Moy et al., "SOD2 functions downstream of Sch9 to extend longevity in yeast," Genetics, vol. 163, no. 1, pp. 35-46, 2003.

[56] P. Fabrizio, S. D. Pletcher, N. Minois, J. W. Vaupel, and V. D. Longo, "Chronological aging-independent replicative life span regulation by Msn2/Msn4 and Sod2 in Saccharomyces cerevisiae," FEBS Letters, vol. 557, no. 1-3, pp. 136-142, 2004.

[57] M. Kaeberlein, R. W. Powers III, K. K. Steffen et al., "Regulation of yeast replicative life span by TOR and Sch9 response to nutrients," Science, vol. 310, no. 5751, pp. 1193-1196, 2005.

[58] R. W. Powers III, M. Kaeberlein, S. D. Caldwell, B. K. Kennedy, and S. Fields, "Extension of chronological life span in yeast by decreased TOR pathway signaling," Genes and Development, vol. 20, no. 2, pp. 174-184, 2006.

[59] T. Vellai, K. Takacs-Vellai, Y. Zhang, A. L. Kovacs, L. Orosz, and F. Müller, "Influence of TOR kinase on lifespan in C. elegans," Nature, vol. 426, no. 6967, p. 620, 2003.

[60] K. Jia, D. Chen, and D. L. Riddle, "The TOR pathway interacts with the insulin signaling pathway to regulate C. elegans larval development, metabolism and life span," Development, vol. 131, no. 16, pp. 3897-3906, 2004.

[61] P. Kapahi, B. M. Zid, T. Harper, D. Koslover, V. Sapin, and S. Benzer, "Regulation of lifespan in Drosophila by modulation of genes in the TOR signaling pathway," Current Biology, vol. 14, p. $885,2004$.

[62] S. Huang and P. J. Houghton, "Inhibitors of mammalian target of rapamycin as novel antitumor agents: from bench to clinic," Current Opinion in Investigational Drugs, vol. 3, no. 2, pp. 295304, 2002.

[63] C. M. Hartford and M. J. Ratain, "Rapamycin: something old, something new, sometimes borrowed and now renewed," Clinical Pharmacology and Therapeutics, vol. 82, no. 4, pp. 381-388, 2007.
[64] M. Mita, K. Sankhala, I. Abdel-Karim, A. Mita, and F. Giles, "Deforolimus (AP23573) a novel mTOR inhibitor in clinical development," Expert Opinion on Investigational Drugs, vol. 17, no. 12, pp. 1947-1954, 2008.

[65] L. Buellesfeld and E. Grube, "ABT-578-eluting stents: the promising successor of sirolimus- and paclitaxel-eluting stent concepts?" Herz, vol. 29, no. 2, pp. 167-170, 2004.

[66] S. E. Burke, R. E. Kuntz, and L. B. Schwartz, "Zotarolimus (ABT578) eluting stents," Advanced Drug Delivery Reviews, vol. 58, no. 3, pp. 437-446, 2006.

[67] K. G. Pike, K. Malagu, M. G. Hummersone et al., “Optimization of potent and selective dual $\mathrm{mTORC} 1$ and $\mathrm{mTORC} 2$ inhibitors: the discovery of AZD8055 and AZD2014," Bioorganic \& Medicinal Chemistry Letters, vol. 23, pp. 1212-1216, 2013.

[68] A. Naing, C. Aghajanian, E. Raymond et al., "Safety, tolerability, pharmacokinetics and pharmacodynamics of AZD8055 in advanced solid tumours and lymphoma," British Journal of Cancer, vol. 107, pp. 1093-1099, 2012.

[69] H. Asahina, H. Nokihara, N. Yamamoto et al., "Safety and tolerability of AZD8055 in Japanese patients with advanced solid tumors; a dose-finding phase I study," Investigational New Drugs, vol. 31, pp. 677-684, 2013.

[70] C. M. Chresta, B. R. Davies, and I. Hickson, "AZD8055 is a potent, selective, and orally bioavailable ATP-competitive mammalian target of rapamycin kinase inhibitor with in vitro and in vivo antitumor activity," Cancer Research, vol. 70, p. 288, 2010.

[71] N. Carayol, E. Vakana, A. Sassano et al., "Critical roles for mTORC2- and rapamycin-insensitive mTORC1-complexes in growth and survival of BCR-ABL-expressing leukemic cells," Proceedings of the National Academy of Sciences of the United States of America, vol. 107, no. 28, pp. 12469-12474, 2010.

[72] S. Schenone, C. Brullo, F. Musumeci, M. Radi, and M. Botta, "ATP-competitive inhibitors of mTOR: an update," Current Medicinal Chemistry, vol. 18, no. 20, pp. 2995-3014, 2011.

[73] K. Yu, C. Shi, L. Toral-Barza et al., "Beyond rapalog therapy: preclinical pharmacology and antitumor activity of WYE-125132, an ATP-competitive and specific inhibitor of mTORC1 and mTORC2," Cancer Research, vol. 70, no. 2, pp. 621-631, 2010.

[74] C. C. Thoreen, S. A. Kang, J. W. Chang et al., "An ATP-competitive mammalian target of rapamycin inhibitor reveals rapamycin-resistant functions of mTORC1," Journal of Biological Chemistry, vol. 284, no. 12, pp. 8023-8032, 2009.

[75] Q.-W. Fan, Z. A. Knight, D. D. Goldenberg et al., "A dual PI3 kinase/mTOR inhibitor reveals emergent efficacy in glioma," Cancer Cell, vol. 9, no. 5, pp. 341-349, 2006.

[76] V. R. Agarwal, A. Joshi, and M. Venkataraman, "Abstract 3759: P7170, a novel inhibitor of phosphoinositide 3-kinase (PI3K)mammalian target of Rapamycin (mTOR) and activin receptorlike kinase 1 (ALK1) as a new therapeutic option for Kras mutated non small cell lung cancer (NSCLC)," Cancer Research, vol. 72, Abstract 3759, 2012.

[77] J. Yuan, P. P. Mehta, M.-J. Yin et al., "PF-04691502, a potent and selective oral inhibitor of PI3K and mTOR kinases with antitumor activity," Molecular Cancer Therapeutics, vol. 10, no. 11, pp. 2189-2199, 2011.

[78] S. J. Shuttleworth, F. A. Silva, A. R. L. Cecil et al., "Progress in the preclinical discovery and clinical development of class I and dual class I/IV phosphoinositide 3-kinase (PI3K) inhibitors," Current Medicinal Chemistry, vol. 18, no. 18, pp. 2686-2714, 2011.

[79] A. M. Venkatesan, C. M. Dehnhardt, E. D. Delos Santos et al., "Bis(morpholino-1,3,5-triazine) derivatives: potent adenosine 
5 -triphosphate competitive phosphatidylinositol-3-kinase/ mammalian target of rapamycin inhibitors: discovery of compound 26 (PKI-587), a highly efficacious dual inhibitor," Journal of Medicinal Chemistry, vol. 53, no. 6, pp. 2636-2645, 2010.

[80] A. M. Venkatesan, Z. Chen, O. D. Santos et al., "PKI-179: an orally efficacious dual phosphatidylinositol-3-kinase (PI3K)/ mammalian target of rapamycin (mTOR) inhibitor," Bioorganic and Medicinal Chemistry Letters, vol. 20, no. 19, pp. 5869-5873, 2010.

[81] G. Prasad, T. Sottero, X. Yang et al., "Inhibition of PI3K/mTOR pathways in glioblastoma and implications for combination therapy with temozolomide," Neuro-Oncology, vol. 13, no. 4, pp. 384-392, 2011.

[82] S.-M. Maira, F. Stauffer, J. Brueggen et al., "Identification and characterization of NVP-BEZ235, a new orally available dual phosphatidylinositol 3-kinase/mammalian target of rapamycin inhibitor with potent in vivo antitumor activity," Molecular Cancer Therapeutics, vol. 7, no. 7, pp. 1851-1863, 2008.

[83] E. Leung, J. E. Kim, G. W. Rewcastle, G. J. Finlay, and B. C. Baguley, "Comparison of the effects of the PI3K/mTOR inhibitors NVP-BEZ235 and GSK2126458 on tamoxifen-resistant breast cancer cells," Cancer Biology and Therapy, vol. 11, no. 11, pp. 938946, 2011.

[84] C. G. Sanchez, C. X. Ma, R. J. Crowder et al., "Preclinical modeling of combined phosphatidylinositol-3-kinase inhibition with endocrine therapy for estrogen receptor-positive breast cancer," Breast Cancer Research, vol. 13, no. 2, article R21, 2011.

[85] B. Markman, J. Tabernero, I. Krop et al., "Phase I safety, pharmacokinetic, and pharmacodynamic study of the oral phosphatidylinositol-3-kinase and mTOR inhibitor BGT226 in patients with advanced solid tumors," Annals of Oncology, vol. 23, pp. 2399-2408, 2012.

[86] D. Mahadevan, E. G. Chiorean, D. D. Von Hoff et al., "Phase I pharmacokinetic and pharmacodynamic study of the panPI3K/mTORC vascular targeted pro-drug SF1126 in patients with advanced solid tumours and B-cell malignancies," European Journal of Cancer, vol. 48, pp. 3319-3327, 2012.

[87] M. Kaeberlein and B. K. Kennedy, "Hot topics in aging research: protein translation and TOR signaling, 2010," Aging Cell, vol. 10, no. 2, pp. 185-190, 2011.

[88] S. D. Katewa and P. Kapahi, "Dietary restriction and aging, 2009," Aging Cell, vol. 9, no. 2, pp. 105-112, 2010.

[89] P. Kapahi, D. Chen, A. N. Rogers et al., "With TOR, less is more: a key role for the conserved nutrient-sensing TOR pathway in aging," Cell Metabolism, vol. 11, no. 6, pp. 453-465, 2010.

[90] J. Gallinetti, E. Harputlugil, and J. R. Mitchell, "Amino acid sensing in dietary-restriction-mediated longevity: roles of signaltransducing kinases GCN2 and TOR," The Biochemical Journal, vol. 449, p. 1, 2013.

[91] U. Kruegel, B. Robison, T. Dange et al., "Elevated proteasome capacity extends replicative lifespan in Saccharomyces cerevisiae," PLoS Genetics, vol. 7, no. 9, Article ID e1002253, 2011.

[92] N. D. Bonawitz, M. Chatenay-Lapointe, Y. Pan, and G. S. Shadel, "Reduced TOR signaling extends chronological life span via increased respiration and upregulation of mitochondrial gene expression," Cell Metabolism, vol. 5, no. 4, pp. 265-277, 2007.

[93] Y. Pan and G. S. Shadel, "Extension of chronological life span by reduced TOR signaling requires down-regulation of Sch9p and involves increased mitochondrial OXPHOS complex density," Aging, vol. 1, no. 1, pp. 131-145, 2009.

[94] M. Hansen, A. Chandra, L. L. Mitic, B. Onken, M. Driscoll, and C. Kenyon, "A role for autophagy in the extension of lifespan by dietary restriction in C. elegans," PLoS Genetics, vol. 4, no. 2, article e24, 2008.

[95] M. Hansen, S. Taubert, D. Crawford, N. Libina, S.-J. Lee, and C. Kenyon, "Lifespan extension by conditions that inhibit translation in Caenorhabditis elegans," Aging Cell, vol. 6, no. 1, pp. 95-110, 2007.

[96] T.-T. Ching, A. B. Paal, A. Mehta, L. Zhong, and A.-L. Hsu, "drr-2 encodes an eIF4H that acts downstream of TOR in dietrestriction-induced longevity of C. elegans," Aging Cell, vol. 9, no. 4, pp. 545-557, 2010.

[97] D. W. Lamming, L. Ye, P. Katajisto et al., "Rapamycin-induced insulin resistance is mediated by mTORC2 loss and uncoupled from longevity," Science, vol. 335, no. 6076, pp. 1638-1643, 2012.

[98] J. J. Wu, J. Liu, E. B. Chen et al., "Increased mammalian lifespan and a segmental and tissue-specific slowing of aging after genetic reduction of mTOR expression," Cell Reports, vol. 4, no. 5, pp. 913-920, 2013.

[99] O. Medvedik, D. W. Lamming, K. D. Kim, and D. A. Sinclair, "MSN2 and MSN4 link calorie restriction and TOR to sirtuinmediated lifespan extension in Saccharomyces cerevisiae," PLoS Biology, vol. 5, no. 10, article e261, 2007.

[100] C. Rallis, S. Codlin, and J. Bahler, “TORC1 signaling inhibition by rapamycin and caffeine affect lifespan, global gene expression, and cell proliferation of fission yeast," Aging Cell, vol. 12, p. 563, 2013.

[101] S. Robida-Stubbs, K. Glover-Cutter, D. W. Lamming et al., “TOR signaling and rapamycin influence longevity by regulating SKN-1/Nrf and DAF-16/FoxO," Cell Metabolism, vol. 15, no. 5, pp. 713-724, 2012.

[102] K. Seo, E. Choi, D. Lee, D. E. Jeong, S. K. Jang, and S. J. Lee, "Heat shock factor 1 mediates the longevity conferred by inhibition of TOR and insulin/IGF-1 signaling pathways in C. elegans," Aging Cell, 2013.

[103] I. Bjedov, J. M. Toivonen, F. Kerr et al., "Mechanisms of life span extension by rapamycin in the fruit fly Drosophila melanogaster," Cell Metabolism, vol. 11, no. 1, pp. 35-46, 2010.

[104] A. A. Moskalev and M. V. Shaposhnikov, "Pharmacological inhibition of phosphoinositide 3 and TOR kinases improves survival of drosophila melanogaster," Rejuvenation Research, vol. 13, no. 2-3, pp. 246-247, 2010.

[105] D. E. Harrison, R. Strong, Z. D. Sharp et al., "Rapamycin fed late in life extends lifespan in genetically heterogeneous mice," Nature, vol. 460, no. 7253, pp. 392-395, 2009.

[106] R. A. Miller, D. E. Harrison, C. M. Astle et al., "Rapamycin, but not resveratrol or simvastatin, extends life span of genetically heterogeneous mice," Journals of Gerontology, vol. 66, pp. 191201, 2011.

[107] J. E. Wilkinson, L. Burmeister, and S. V. Brooks, "Rapamycin slows aging in mice," Aging Cell, vol. 11, pp. 675-682, 2012.

[108] V. N. Anisimov, M. A. Zabezhinski, I. G. Popovich et al., "Rapamycin increases lifespan and inhibits spontaneous tumorigenesis in inbred female mice," Cell Cycle, vol. 10, no. 24, pp. 4230-4236, 2011.

[109] F. Neff et al., "Rapamycin extends murine lifespan but has limited effects on aging," The Journal of Clinical Investigation, vol. 123, pp. 3272-3291, 2013.

[110] Y. Zhang, A. Bokov, J. Gelfond et al., "Rapamycin extends life and health in C57BL/6 mice," Journal of Gerontology, 2013.

[111] C. Chen, Y. Liu, Y. Liu, and P. Zheng, "MTOR regulation and therapeutic rejuvenation of aging hematopoietic stem cells," Science Signaling, vol. 2, no. 98, p. ra75, 2009. 
[112] A. E. Roux, A. Quissac, P. Chartrand, G. Ferbeyre, and L. A. Rokeach, "Regulation of chronological aging in Schizosaccharomyces pombe by the protein kinases Pkal and Sck2," Aging Cell, vol. 5, no. 4, pp. 345-357, 2006.

[113] K. Z. Pan, J. E. Palter, A. N. Rogers et al., "Inhibition of mRNA translation extends lifespan in Caenorhabditis elegans," Aging Cell, vol. 6, no. 1, pp. 111-119, 2007.

[114] D. Chen, E. L. Thomas, and P. Kapahi, "HIF-1 modulates dietary restriction-mediated lifespan extension via IRE-1 in Caenorhabditis elegans," PLoS Genetics, vol. 5, no. 5, Article ID e1000486, 2009.

[115] B. M. Zid, A. N. Rogers, S. D. Katewa et al., "4E-BP extends lifespan upon dietary restriction by enhancing mitochondrial activity in Drosophila," Cell, vol. 139, no. 1, pp. 149-160, 2009.

[116] C. Selman, J. M. Tullet, D. Wieser et al., "Ribosomal protein S6 kinase 1 signaling regulates mammalian life span," Science, vol. 326, pp. 140-144, 2009.

[117] R. Mehta, D. Chandler-Brown, F. J. Ramos, L. S. Shamieh, and M. Kaeberlein, "Regulation of mRNA translation as a conserved mechanism of longevity control," Advances in Experimental Medicine and Biology, vol. 694, pp. 14-29, 2010.

[118] B. K. Kennedy and M. Kaeberlein, "Hot topics in aging research: protein translation, 2009," Aging Cell, vol. 8, no. 6, pp. 617-623, 2009.

[119] P. Syntichaki, K. Troulinaki, and N. Tavernarakis, "eIF4E function in somatic cells modulates ageing in Caenorhabditis elegans," Nature, vol. 445, no. 7130, pp. 922-926, 2007.

[120] S. P. Curran and G. Ruvkun, "Lifespan regulation by evolutionarily conserved genes essential for viability," PLoS Genetics, vol. 3, no. 4, e56, 2007.

[121] J. R. Managbanag, T. M. Witten, D. Bonchev et al., "Shortestpath network analysis is a useful approach toward indentifying genetic determinants of longevity," PLoS ONE, vol. 3, no. 11, Article ID e3802, 2008.

[122] E. D. Smith, M. Tsuchiya, L. A. Fox et al., "Quantitative evidence for conserved longevity pathways between divergent eukaryotic species," Genome Research, vol. 18, no. 4, pp. 564-570, 2008.

[123] K. K. Steffen, V. L. MacKay, E. O. Kerr et al., "Yeast life span extension by depletion of $60 \mathrm{~S}$ ribosomal subunits is mediated by Gcn4," Cell, vol. 133, no. 2, pp. 292-302, 2008.

[124] K. K. Steffen, M. A. McCormick, K. M. Pham et al., "Ribosome deficiency protects against ER stress in Saccharomyces cerevisiae," Genetics, vol. 191, no. 1, pp. 107-118, 2012.

[125] A. Chiocchetti, J. Zhou, H. Zhu et al., "Ribosomal proteins Rpl10 and Rps6 are potent regulators of yeast replicative life span," Experimental Gerontology, vol. 42, no. 4, pp. 275-286, 2007.

[126] S. Gelino and M. Hansen, "Autophagy—an emerging anti-aging mechanism," Journal of Clinical \& Experimental Pathology, 2012.

[127] E. Lionaki, M. Markaki, and N. Tavernarakis, "Autophagy and ageing: insights from invertebrate model organisms," Ageing Research Reviews, vol. 12, p. 413, 2013.

[128] A. M. Cuervo, "Autophagy and aging: keeping that old broom working," Trends in Genetics, vol. 24, no. 12, pp. 604-612, 2008.

[129] J.-O. Pyo, S.-M. Yoo, and H. H. Ahn, "Overexpression of Atg5 in mice activates autophagy and extends lifespan," Nature Communications, vol. 4, p. 2300, 2013.

[130] R. A. Miller, D. E. Harrison, C. M. Astle et al., "An aging interventions testing program: study design and interim report," Aging Cell, vol. 6, no. 4, pp. 565-575, 2007.

[131] N. L. Nadon, R. Strong, R. A. Miller et al., "Design of aging intervention studies: the NIA interventions testing program," Age, vol. 30, no. 4, pp. 187-199, 2008.
[132] M. Kaeberlein and B. K. Kennedy, "Ageing: a midlife longevity drug?” Nature, 2009.

[133] M. Kaeberlein, "Resveratrol and rapamycin: are they anti-aging drugs?” BioEssays, vol. 32, no. 2, pp. 96-99, 2010.

[134] M. Kaeberlein and P. Kapahi, "Aging is RSKY business," Science, vol. 326, no. 5949, pp. 55-56, 2009.

[135] J. L. Kirkland and C. Peterson, "Healthspan, translation, and new outcomes for animal studies of aging," Journals of Gerontology A, vol. 64, no. 2, pp. 209-212, 2009.

[136] M. Tatar, "Can we develop genetically tractable models to assess healthspan (rather than life span) in animal models?" Journals of Gerontology A, vol. 64, no. 2, pp. 161-163, 2009.

[137] M. V. Blagosklonny, "Prospective treatment of age-related diseases by slowing down aging," The American Journal of Pathology, vol. 181, p. 1142, 2012.

[138] D. S. Evans, P. Kapahi, W.-C. Hsueh, and L. Kockel, “TOR signaling never gets old: aging, longevity and TORC1 activity," Ageing Research Reviews, vol. 10, no. 2, pp. 225-237, 2011.

[139] M. Kaeberlein and B. K. Kennedy, "Protein translation, 2008," Aging Cell, vol. 7, no. 6, pp. 777-782, 2008.

[140] M. Cornu, V. Albert, and M. N. Hall, "mTOR in aging, metabolism, and cancer," Current Opinion in Genetics \& Development, vol. 23, p. 53, 2013.

[141] P. Hasty, Z. D. Sharp, T. J. Curiel, and J. Campisi, "mTORC1 and p53: clash of the gods?" Cell Cycle, vol. 12, p. 20, 2013.

[142] F. J. Ramos and M. Kaeberlein, "Ageing: a healthy diet for stem cells," Nature, vol. 486, p. 477, 2012.

[143] C. Lerner, A. Bitto, D. Pulliam et al., "Reduced mammalian target of rapamycin activity facilitates mitochondrial retrograde signaling and increases life span in normal human fibroblasts," Aging Cell, 2013.

[144] T. V. Pospelova, "Suppression of replicative senescence by rapamycin in rodent embryonic cells," Cell Cycle, vol. 11, pp. 24022407, 2012.

[145] V. Dulic, "Senescence regulation by mTOR," Methods in Molecular Biology, vol. 965, p. 15, 2013.

[146] E. Dazert and M. N. Hall, "MTOR signaling in disease," Current Opinion in Cell Biology, vol. 23, no. 6, pp. 744-755, 2011.

[147] Z. Yang and X. F. Ming, "mTOR signalling: the molecular interface connecting metabolic stress, aging and cardiovascular diseases," Obesity Reviews, vol. 13, supplement 2, p. 58, 2012.

[148] J. Bové, M. Martínez-Vicente, and M. Vila, "Fighting neurodegeneration with rapamycin: mechanistic insights," Nature Reviews Neuroscience, vol. 12, no. 8, pp. 437-452, 2011.

[149] E. Aso and I. Ferrer, "It may be possible to delay the onset of neurodegenerative diseases with an immunosuppressive drug (rapamycin)," Expert Opinion on Biological Therapy, vol. 13, p. 1215, 2013.

[150] E. Wong and A. M. Cuervo, "Autophagy gone awry in neurodegenerative diseases," Nature Neuroscience, vol. 13, no. 7, pp. 805811, 2010.

[151] D. C. Rubinsztein, “The roles of intracellular protein-degradation pathways in neurodegeneration," Nature, vol. 443, no. 7113, pp. 780-786, 2006.

[152] C. Malagelada, Z. H. Jin, V. Jackson-Lewis, S. Przedborski, and L. A. Greene, "Rapamycin protects against neuron death in in vitro and in vivo models of Parkinson's disease," Journal of Neuroscience, vol. 30, no. 3, pp. 1166-1175, 2010.

[153] L. S. Tain, H. Mortiboys, R. N. Tao, E. Ziviani, O. Bandmann, and A. J. Whitworth, "Rapamycin activation of 4E-BP prevents 
parkinsonian dopaminergic neuron loss," Nature Neuroscience, vol. 12, no. 9, pp. 1129-1135, 2009.

[154] K. Liu, N. Shi, Y. Sun, T. Zhang, and X. Sun, "Therapeutic effects of rapamycin on MPTP-induced Parkinsonism in mice," Neurochemical Research, vol. 38, p. 201, 2013.

[155] B. Ravikumar, C. Vacher, Z. Berger et al., "Inhibition of mTOR induces autophagy and reduces toxicity of polyglutamine expansions in fly and mouse models of Huntington disease," Nature Genetics, vol. 36, no. 6, pp. 585-595, 2004.

[156] A. Roscic, B. Baldo, C. Crochemore, D. Marcellin, and P. Paganetti, "Induction of autophagy with catalytic mTOR inhibitors reduces huntingtin aggregates in a neuronal cell model," Journal of Neurochemistry, vol. 119, no. 2, pp. 398-407, 2011.

[157] S. Oddo, "The role of mTOR signaling in Alzheimer disease," Frontiers in Bioscience, vol. 4, p. 941, 2012.

[158] Y. X. Sun, X. Ji, X. Mao et al., "Differential activation of mTOR complex 1 signaling in human brain with mild to severe Alzheimer's disease," Journal of Alzheimer's Disease, 2013.

[159] S. Majumder, A. Richardson, R. Strong, and S. Oddo, "Inducing autophagy by rapamycin before, but not after, the formation of plaques and tangles ameliorates cognitive deficits," PLoS ONE, vol. 6, no. 9, Article ID e25416, 2011.

[160] P. Spilman, N. Podlutskaya, M. J. Hart et al., "Inhibition of mTOR by rapamycin abolishes cognitive deficits and reduces amyloid- $\beta$ levels in a mouse model of alzheimer's disease," PLoS ONE, vol. 5, no. 4, Article ID e9979, 2010.

[161] A. L. Lin, W. Zheng, J. J. Halloran et al., "Chronic rapamycin restores brain vascular integrity and function through NO synthase activation and improves memory in symptomatic mice modeling Alzheimer's disease," Journal of Cerebral Blood Flow and Metabolism, vol. 33, p. 1412, 2013.

[162] C. A. Hoeffer and E. Klann, "mTOR signaling: at the crossroads of plasticity, memory and disease," Trends in Neurosciences, vol. 33, no. 2, pp. 67-75, 2010.

[163] J. Halloran, S. A. Hussong, R. Burbank et al., "Chronic inhibition of mammalian target of rapamycin by rapamycin modulates cognitive and non-cognitive components of behavior throughout lifespan in mice," Neuroscience, vol. 223, pp. 102-113, 2012.

[164] S. Majumder, A. Caccamo, D. X. Medina et al., "Lifelong rapamycin administration ameliorates age-dependent cognitive deficits by reducing IL- $1 \beta$ and enhancing NMDA signaling," Aging Cell, vol. 11, no. 2, pp. 326-335, 2012.

[165] J. Xie and T. P. Herbert, "The role of mammalian target of rapamycin (mTOR) in the regulation of pancreatic $\beta$-cell mass: implications in the development of type-2 diabetes," Cellular and Molecular Life Sciences, vol. 69, pp. 1289-1304, 2012.

[166] K. Garber, "Targeting mTOR: something old, something new," Journal of the National Cancer Institute, vol. 101, no. 5, pp. 288290, 2009.

[167] M. V. Blagosklonny, "Rapalogs in cancer prevention: anti-aging or anticancer?” Cancer Biology \& Therapy, vol. 13, p. 1349, 2012.

[168] Z. D. Sharp and A. Richardson, "Aging and cancer: can mTOR inhibitors kill two birds with one drug?" Targeted Oncology, vol. 6, no. 1, pp. 41-51, 2011.

[169] E. A. Komarova, M. P. Antoch, L. R. Novototskaya et al., "Rapamycin extends lifespan and delays tumorigenesis in heterozygous p53+/- mice," Aging, vol. 4, pp. 709-714, 2012.

[170] C. B. Livi, R. L. Hardman, B. A. Christy et al., "Rapamycin extends life span of Rb1+/- mice by inhibiting neuroendocrine tumors," Aging, vol. 5, pp. 100-110, 2013.
[171] A. Arcella, F. Biagioni, M. Antonietta Oliva et al., "Rapamycin inhibits the growth of glioblastoma," Brain Research, vol. 1495, pp. 37-51, 2013.

[172] O. Ekshyyan, T. N. Moore-Medlin, M. C. Raley et al., "Anti-lymphangiogenic properties of mTOR inhibitors in head and neck squamous cell carcinoma experimental models," BMC Cancer, vol. 13, article 320, 2013.

[173] J. E. Hartwich, W. S. Orr, and C.Y. Ng, "Rapamycin increases neuroblastoma xenograft and host stromal derived osteoprotegerin inhibiting osteolytic bone disease in a bone metastasis model," Journal of Pediatric Surgery, vol. 48, pp. 47-55, 2013.

[174] S. Z. Kaylani, J. Xu, R. K. Srivastava et al., "Rapamycin targeting mTOR and hedgehog signaling pathways blocks human rhabdomyosarcoma growth in xenograft murine model," Biochemical and Biophysical Research Communications, vol. 435, pp. 557561, 2013.

[175] T. Nishikawa, M. Takaoka, T. Ohara et al., "Antiproliferative effect of a novel mTOR inhibitor temsirolimus contributes to the prolonged survival of orthotopic esophageal cancer-bearing mice," Cancer Biology \& Therapy, vol. 14, pp. 230-236, 2013.

[176] D. Pachow, N. Andrae, N. Kliese et al., "mTORC1 inhibitors suppress meningioma growth in mouse models," Clinical Cancer Research, vol. 19, p. 1180, 2013.

[177] R. J. O. Dowling, I. Topisirovic, B. D. Fonseca, and N. Sonenberg, "Dissecting the role of mTOR: lessons from mTOR inhibitors," Biochimica et Biophysica Acta, vol. 1804, no. 3, pp. 433-439, 2010.

[178] A. Fasolo and C. Sessa, "Targeting mTOR pathways in human malignancies," Current Pharmaceutical Design, vol. 18, p. 2766, 2012.

[179] J. M. Flynn, "Late-life rapamycin treatment reverses age-related heart dysfunction," Aging Cell, vol. 12, no. 5, pp. 851-862, 2013.

[180] J. Sadoshima and S. Izumo, "Rapamycin selectively inhibits angiotensin II-induced increase in protein synthesis in cardiac myocytes in vitro: potential role of $70-\mathrm{kD}$ S6 kinase in angiotensin II-induced cardiac hypertrophy," Circulation Research, vol. 77, no. 6, pp. 1040-1052, 1995.

[181] T. Shioi, J. R. McMullen, O. Tarnavski et al., "Rapamycin attenuates load-induced cardiac hypertrophy in mice," Circulation, vol. 107, no. 12, pp. 1664-1670, 2003.

[182] J. R. McMullen, M. C. Sherwood, O. Tarnavski et al., "Inhibition of mTOR signaling with rapamycin regresses established cardiac hypertrophy induced by pressure overload," Circulation, vol. 109, no. 24, pp. 3050-3055, 2004.

[183] J. A. Kuzman, T. D. O'Connell, and A. M. Gerdes, "Rapamycin prevents thyroid hormone-induced cardiac hypertrophy," Endocrinology, vol. 148, no. 7, pp. 3477-3484, 2007.

[184] S. A. Khan, F. Salloum, A. Das, L. Xi, G. W. Vetrovec, and R. C. Kukreja, "Rapamycin confers preconditioning-like protection against ischemia-reperfusion injury in isolated mouse heart and cardiomyocytes," Journal of Molecular and Cellular Cardiology, vol. 41, no. 2, pp. 256-264, 2006.

[185] A. Das, F. N. Salloum, D. Durrant, R. Ockaili, and R. C. Kukreja, "Rapamycin protects against myocardial ischemia-reperfusion injury through JAK2-STAT3 signaling pathway," Journal of Molecular and Cellular Cardiology, vol. 53, p. 858, 2012.

[186] T. M. Marin, K. Keith, B. Davies et al., "Rapamycin reverses hypertrophic cardiomyopathy in a mouse model of LEOPARD syndrome-associated PTPN11 mutation," Journal of Clinical Investigation, vol. 121, no. 3, pp. 1026-1043, 2011. 
[187] K. Xie, B. Jin, Y. Li et al., "Modulating autophagy improves cardiac function in a rat model of early-stage dilated cardiomyopathy," Cardiology, vol. 125, no. 1, pp. 60-68, 2013.

[188] F. J. Ramos, S. C. Chen, M. G. Garelick et al., "Rapamycin reverses elevated $\mathrm{mTORC1}$ signaling in lamin A/C-deficient mice, rescues cardiac and skeletal muscle function, and extends survival," Science Translational Medicine, vol. 4, p. 144ra103, 2012.

[189] J. C. Choi and H. J. Worman, "Reactivation of autophagy ameliorates LMNA cardiomyopathy," Autophagy, vol. 9, p. 110, 2013.

[190] J. C. Choi, A. Muchir, W. Wu et al., "Temsirolimus activates autophagy and ameliorates cardiomyopathy caused by lamin A/C gene mutation," Science Translational Medicine, vol. 4, p. 144ra102, 2012.

[191] Y. Ding, X. Sun, W. Huang et al., "Haploinsufficiency of target of rapamycin attenuates cardiomyopathies in adult zebrafish," Circulation Research, vol. 109, no. 6, pp. 658-669, 2011.

[192] J. M. Carrascosa, M. Ros, A. Andrés, T. Fernández-Agulló, and C. Arribas, "Changes in the neuroendocrine control of energy homeostasis by adiposity signals during aging," Experimental Gerontology, vol. 44, no. 1-2, pp. 20-25, 2009.

[193] A. M. Chang and J. B. Halter, "Effects of aging on glucose homeostasis," in DiabetesMellitus: A Fundamental and Clinical Text, D. Le Roith, S. I. Taylor, and J. M. Olefsky, Eds., pp. 869-877, Lippincott Williams \& Wilkins, 2004.

[194] J. Chen, "Multiple signal pathways in obesity-associated cancer," Obesity Reviews, vol. 12, no. 12, pp. 1063-1070, 2011.

[195] I. Bakan and M. Laplante, "Connecting mTORC1 signaling to SREBP-1 activation," Current Opinion in Lipidology, vol. 2, p. 226, 2012.

[196] M. Pende, S. C. Kozma, M. Jaquet et al., "Hypoinsulinaemia, glucose intolerance and diminished $\beta$-cell size in S6K1-deficient mice," Nature, vol. 408, no. 6815, pp. 994-997, 2000.

[197] P. Polak, N. Cybulski, J. N. Feige, J. Auwerx, M. A. Rüegg, and M. N. Hall, "Adipose-specific knockout of raptor results in lean mice with enhanced mitochondrial respiration," Cell Metabolism, vol. 8, no. 5, pp. 399-410, 2008.

[198] S. H. Um, F. Frigerio, M. Watanabe et al., "Absence of S6K1 protects against age- and diet-induced obesity while enhancing insulin sensitivity," Nature, vol. 431, pp. 200-205, 2004.

[199] A. D. Barlow, M. L. Nicholson, and T. P. Herbert, "Evidence for rapamycin toxicity in pancreatic beta-cells and a review of the underlying molecular mechanisms," Diabetes, vol. 62, p. 2674 , 2013.

[200] S. S. Deepa, M. E. Walsh, R. T. Hamilton et al., "Rapamycin modulates markers of mitochondrial biogenesis and fatty acid oxidation in the adipose tissue of $\mathrm{db} / \mathrm{db}$ mice," Journal of Biochemical and Pharmacological Research, vol. 1, pp. 114-123, 2013.

[201] M. V. Blagosklonny, "Once again on rapamycin-induced insulin resistance and longevity: despite of or owing to," Aging, vol. 4, p. 350, 2012.

[202] C. Jagannath and P. Bakhru, "Rapamycin-induced enhancement of vaccine efficacy in mice," Methods in Molecular Biology, vol. 821, pp. 295-303, 2012.

[203] E. Amiel, B. Everts, and T. C. Freitas, "Inhibition of mechanistic target of rapamycin promotes dendritic cell activation and enhances therapeutic autologous vaccination in mice," Journal of Immunology, vol. 189, no. 5, pp. 2151-2158, 2012.

[204] K. Araki, A. P. Turner, V. O. Shaffer et al., "mTOR regulates memory CD8 T-cell differentiation," Nature, vol. 460, no. 7251, pp. 108-112, 2009.
[205] S. Anand, K. L. Johansen, and M. Kurella Tamura, "Aging and chronic kidney disease: the impact on physical function and cognition," Journal of Gerontology, 2013.

[206] P. Stenvinkel and T. E. Larsson, "Chronic kidney disease: a clinical model of premature aging," American Journal of Kidney Diseases, vol. 62, p. 339, 2013.

[207] W. Lieberthal and J. S. Levine, "Mammalian target of rapamycin and the kidney-II. Pathophysiology and therapeutic implications," American Journal of Physiology: Renal Physiology, vol. 303, p. F180, 2012.

[208] E. Leung and G. Landa, "Update on current and future novel therapies for dry age-related macular degeneration," Expert Review of Clinical Pharmacology, 2013.

[209] A. Stahl, L. Paschek, G. Martin et al., "Rapamycin reduces VEGF expression in retinal pigment epithelium (RPE) and inhibits RPE-induced sprouting angiogenesis in vitro," FEBS Letters, vol. 582, no. 20, pp. 3097-3102, 2008.

[210] N. G. Kolosova, N. A. Muraleva, A. A. Zhdankina, N. A. Stefanova, A. Z. Fursova, and M. V. Blagosklonny, "Prevention of agerelated macular degeneration-like retinopathy by rapamycin in rats," American Journal of Pathology, vol. 181, pp. 472-477, 2012.

[211] R. B. Nussenblatt, G. Byrnes, H. N. Sen et al., "A randomized pilot study of systemic immunosuppression in the treatment of age-related macular degeneration with choroidal neovascularization," Retina, vol. 30, no. 10, pp. 1579-1587, 2010.

[212] C. R. Burtner and B. K. Kennedy, "Progeria syndromes and ageing: what is the connection?" Nature Reviews Molecular Cell Biology, vol. 11, no. 8, pp. 567-578, 2010.

[213] K. Cao, J. J. Graziotto, C. D. Blair et al., "Rapamycin reverses cellular phenotypes and enhances mutant protein clearance in Hutchinson-Gilford progeria syndrome cells," Science Translational Medicine, vol. 3, no. 89, p. 89ra58, 2011.

[214] J. J. Graziotto, K. Cao, F. S. Collins, and D. Krainc, "Rapamycin activates autophagy in Hutchinson-Gilford progeria syndrome: implications for normal aging and age-dependent neurodegenerative disorders," Autophagy, vol. 8, no. 1, pp. 147-151, 2012.

[215] P. Curatolo, R. Bombardieri, and S. Jozwiak, "Tuberous sclerosis," The Lancet, vol. 372, no. 9639, pp. 657-668, 2008.

[216] J. P. Osborne, A. Fryer, and D. Webb, "Epidemiology of tuberous sclerosis," Annals of the New York Academy of Sciences, vol. 615, pp. 125-127, 1991.

[217] P. B. Crino, K. L. Nathanson, and E. P. Henske, "The tuberous sclerosis complex," The New England Journal of Medicine, vol. 355, no. 13, pp. 1345-1356, 2006.

[218] K. Ridler, J. Suckling, N. J. Higgins et al., "Neuroanatomical correlates of memory deficits in tuberous sclerosis complex," Cerebral Cortex, vol. 17, no. 2, pp. 261-271, 2007.

[219] S. L. Smalley, "Autism and tuberous sclerosis," Journal of Autism and Developmental Disorders, vol. 28, no. 5, pp. 407-414, 1998.

[220] P. Prather and P. J. de Vries, "Behavioral and cognitive aspects of tuberous sclerosis complex," Journal of Child Neurology, vol. 19, no. 9, pp. 666-674, 2004.

[221] P. Curatolo and R. Moavero, "mTOR inhibitors as a new therapeutic option for epilepsy," Expert Review of Neurotherapeutics, vol. 13, p. 627, 2013.

[222] J. R. Sampson, "Therapeutic targeting of mTOR in tuberous sclerosis," Biochemical Society Transactions, vol. 37, no. 1, pp. 259-264, 2009.

[223] L. Meikle, K. Pollizzi, A. Egnor et al., "Response of a neuronal model of tuberous sclerosis to mammalian target of rapamycin (mTOR) inhibitors: effects on mTORC1 and Akt signaling lead 
to improved survival and function," Journal of Neuroscience, vol. 28, no. 21, pp. 5422-5432, 2008.

[224] N. Lee, C. L. Woodrum, A. M. Nobil, A. E. Rauktys, M. P. Messina, and S. L. Dabora, "Rapamycin weekly maintenance dosing and the potential efficacy of combination sorafenib plus rapamycin but not atorvastatin or doxycycline in tuberous sclerosis preclinical models," BMC Pharmacology, vol. 9, p. 8, 2009.

[225] M. Wong, "A critical review of mTOR inhibitors and epilepsy: from basic science to clinical trials," Expert Review of Neurotherapeutics, vol. 13, p. 657, 2013.

[226] D. A. Krueger, M. M. Care, K. Holland et al., "Everolimus for subependymal giant-cell astrocytomas in tuberous sclerosis," New England Journal of Medicine, vol. 363, no. 19, pp. 1801-1811, 2010.

[227] R. Moavero, M. Pinci, R. Bombardieri, and P. Curatolo, "The management of subependymal giant cell tumors in tuberous sclerosis: a clinician's perspective," Child's Nervous System, vol. 27, no. 8, pp. 1203-1210, 2011.

[228] J. J. Bissler, F. X. McCormack, L. R. Young et al., "Sirolimus for angiomyolipoma in tuberous sclerosis complex or lymphangioleiomyomatosis," New England Journal of Medicine, vol. 358, no. 2, pp. 140-151, 2008.

[229] D. M. Davies, P. J. De Vries, S. R. Johnson et al., "Sirolimus therapy for angiomyolipoma in tuberous sclerosis and sporadic lymphangioleiomyomatosis: a phase 2 trial," Clinical Cancer Research, vol. 17, no. 12, pp. 4071-4081, 2011.

[230] D. M. Davies, S. R. Johnson, A. E. Tattersfield et al., "Sirolimus therapy in tuberous sclerosis or sporadic lymphangioleiomyomatosis," New England Journal of Medicine, vol. 358, no. 2, pp. 200-203, 2008.

[231] T. T. Gipson and M. V. Johnston, "Plasticity and mTOR: towards restoration of impaired synaptic plasticity in mTOR-related neurogenetic disorders," Neural Plasticity, vol. 2012, Article ID 486402, 10 pages, 2012.

[232] X. F. Meng, J. T. Yu, J. H. Song, S. Chi, and L. Tan, "Role of the mTOR signaling pathway in epilepsy," Journal of the Neurological Sciences, vol. 332, p. 4, 2013.

[233] M. Wong and P. B. Crino, Jasper's Basic Mechanisms of the Epilepsies, edited by J. L. Noebels, M. Avoli, M. A. Rogawski, R. W. Olsen, A. V. Delgado-Escueta, Bethesda, Md, USA, 2012.

[234] C.-H. Kwon, X. Zhu, J. Zhang, and S. J. Baker, "mTor is required for hypertrophy of Pten-deficient neuronal soma in vivo," Proceedings of the National Academy of Sciences of the United States of America, vol. 100, no. 22, pp. 12923-12928, 2003.

[235] A. S. Galanopoulou, J. A. Gorter, and C. Cepeda, "Finding a better drug for epilepsy: the mTOR pathway as an antiepileptogenic target," Epilepsia, vol. 53, p. 1119, 2012.

[236] K. Heng, M. M. Haney, and P. S. Buckmaster, "High-dose rapamycin blocks mossy fiber sprouting but not seizures in a mouse model of temporal lobe epilepsy," Epilepsia, vol. 54, p. 1535, 2013.

[237] P. F. Bolton, R. J. Park, J. N. P. Higgins, P. D. Griffiths, and A. Pickles, "Neuro-epileptic determinants of autism spectrum disorders in tuberous sclerosis complex," Brain, vol. 125, no. 6, pp. 1247-1255, 2002.

[238] E. Fombonne, "Epidemiological surveys of autism and other pervasive developmental disorders: an update," Journal of Autism and Developmental Disorders, vol. 33, no. 4, pp. 365-382, 2003.

[239] M. G. Butler, M. J. Dazouki, X.-P. Zhou et al., "Subset of individuals with autism spectrum disorders and extreme macrocephaly associated with germline PTEN tumour suppressor gene mutations," Journal of Medical Genetics, vol. 42, no. 4, pp. 318-321, 2005.

[240] M. Neves-Pereira, B. Müller, D. Massie et al., "Deregulation of EIF4E: a novel mechanism for autism," Journal of Medical Genetics, vol. 46, no. 11, pp. 759-765, 2009.

[241] D. Ehninger and A. J. Silva, "Rapamycin for treating Tuberous sclerosis and Autism spectrum disorders," Trends in Molecular Medicine, vol. 17, no. 2, pp. 78-87, 2011.

[242] J. Hughes, C. J. Ward, B. Peral et al., "The polycystic kidney disease 1 (PKD1) gene encodes a novel protein with multiple cell recognition domains," Nature Genetics, vol. 10, no. 2, pp. 151$160,1995$.

[243] T. Weimbs, "Regulation of mTOR by polycystin-1: is polycystic kidney disease a case of futile repair?" Cell Cycle, vol. 5, no. 21, pp. 2425-2429, 2006.

[244] J. M. Shillingford, N. S. Murcia, C. H. Larson et al., “The mTOR pathway is regulated by polycystin-1, and its inhibition reverses renal cystogenesis in polycystic kidney disease," Proceedings of the National Academy of Sciences of the United States of America, vol. 103, no. 14, pp. 5466-5471, 2006.

[245] S. M. Flechner, D. Goldfarb, C. Modlin et al., "Kidney transplantation without calcineurin inhibitor drugs: a prospective, randomized trial of sirolimus versus cyclosporine," Transplantation, vol. 74, no. 8, pp. 1070-1076, 2002.

[246] G. Stallone, B. Infante, G. Grandaliano et al., "Rapamycin for treatment of type I autosomal dominant polycystic kidney disease (RAPYD-study): a randomized, controlled study," Nephrology, Dialysis, Transplantation, vol. 27, pp. 3560-3567, 2012.

[247] N. Perico and G. Remuzzi, "Do mTOR inhibitors still have a future in ADPKD?" Nature Reviews, vol. 6, no. 12, pp. 696-698, 2010.

[248] N. Perico, L. Antiga, A. Caroli et al., "Sirolimus therapy to halt the progression of ADPKD," Journal of the American Society of Nephrology, vol. 21, no. 6, pp. 1031-1040, 2010.

[249] I. Obara, S. M. Géranton, and S. P. Hunt, "Axonal protein synthesis: a potential target for pain relief?" Current Opinion in Pharmacology, vol. 12, no. 1, pp. 42-48, 2012.

[250] S. M. Géranton, L. Jiménez-Díaz, C. Torsney et al., "A rapamycin-sensitive signaling pathway is essential for the full expression of persistent pain states," Journal of Neuroscience, vol. 29, no. 47, pp. 15017-15027, 2009.

[251] E. Norsted Gregory, S. Codeluppi, J. A. Gregory, J. Steinauer, and C. I. Svensson, "Mammalian target of rapamycin in spinal cord neurons mediates hypersensitivity induced by peripheral inflammation," Neuroscience, vol. 169, no. 3, pp. 1392-1402, 2010.

[252] I. Obara, K. K. Tochiki, S. M. Géranton et al., "Systemic inhibition of the mammalian target of rapamycin (mTOR) pathway reduces neuropathic pain in mice," Pain, vol. 152, no. 11, pp. 2582-2595, 2011.

[253] W. Zhang, X. F. Sun, and J. H. Bo, "Activation of mTOR in the spinal cord is required for pain hypersensitivity induced by chronic constriction injury in mice," Pharmacology, Biochemistry, and Behavior, vol. 111, pp. 64-70, 2013.

[254] L. Jiménez-Díaz, S. M. Géranton, G. M. Passmore et al., "Local translation in primary afferent fibers regulates nociception," PLoS ONE, vol. 3, no. 4, Article ID e1961, 2008.

[255] D. Guo, L. Zeng, D. L. Brody, and M. Wong, "Rapamycin attenuates the development of posttraumatic epilepsy in a mouse model of traumatic brain injury," PLoS ONE, vol. 8, Article ID e64078, 2013. 
[256] A. S. Don, C. K. Tsang et al., "Targeting mTOR as a novel therapeutic strategy for traumatic CNS injuries," Drug Discovery Today, vol. 17, pp. 861-868, 2012.

[257] J. Park, J. Zhang, J. Qiu et al., "Combination therapy targeting Akt and mammalian target of rapamycin improves functional outcome after controlled cortical impact in mice," Journal of Cerebral Blood Flow and Metabolism, vol. 32, no. 2, pp. 330-340, 2012.

[258] S. Erlich, A. Alexandrovich, E. Shohami, and R. Pinkas-Kramarski, "Rapamycin is a neuroprotective treatment for traumatic brain injury," Neurobiology of Disease, vol. 26, no. 1, pp. 86-93, 2007.

[259] J. Wang, K. Lu, F. Liang et al., "Decreased autophagy contributes to myocardial dysfunction in rats subjected to nonlethal mechanical trauma," PLoS ONE, vol. 8, Article ID e71400, 2013.

[260] P. Tang, H. Hou, L. Zhang et al., "Autophagy reduces neuronal damage and promotes locomotor recovery via inhibition of apoptosis after spinal cord injury in rats," Molecular Neurobiology, 2013. 

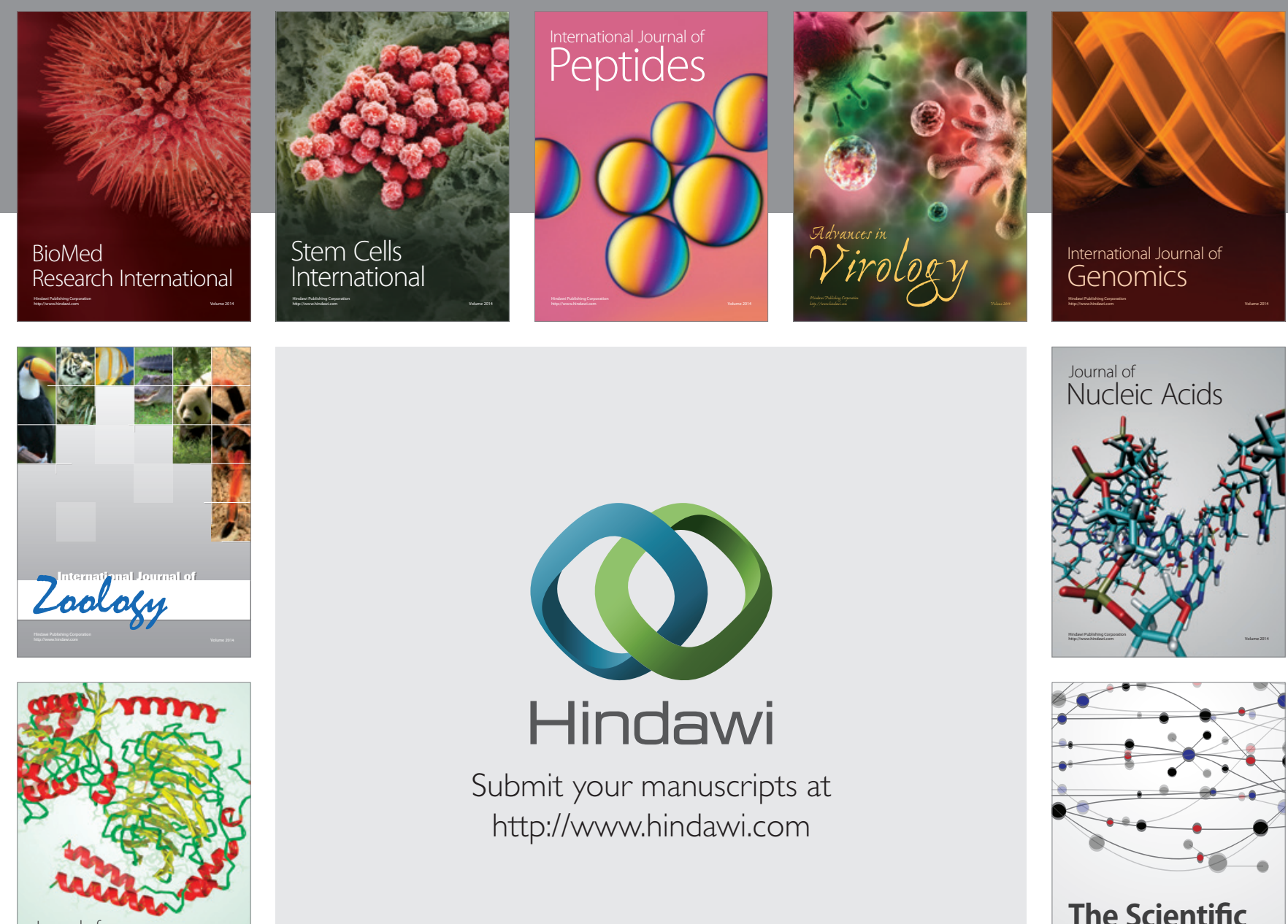

Submit your manuscripts at

http://www.hindawi.com

Journal of
Signal Transduction
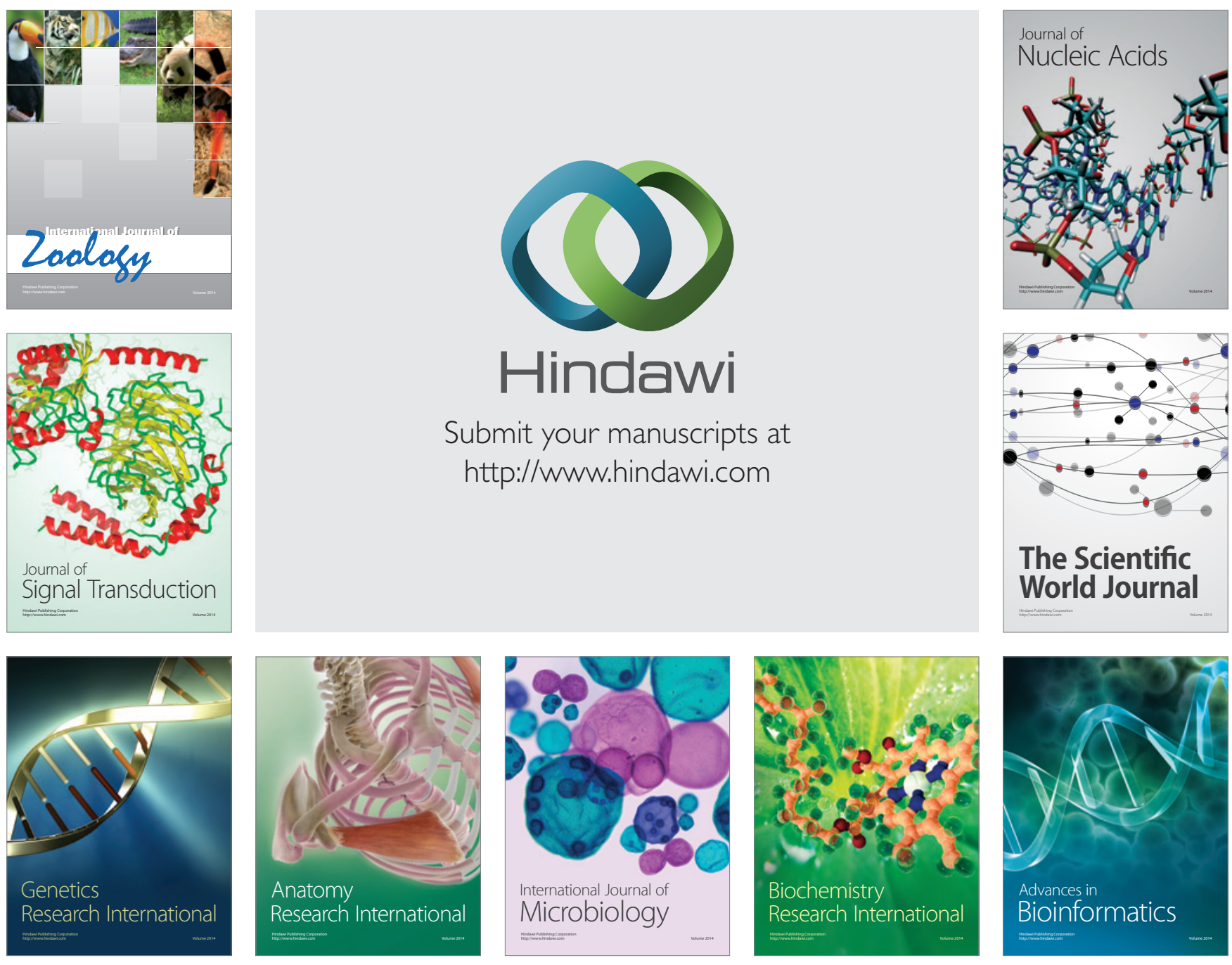

The Scientific World Journal
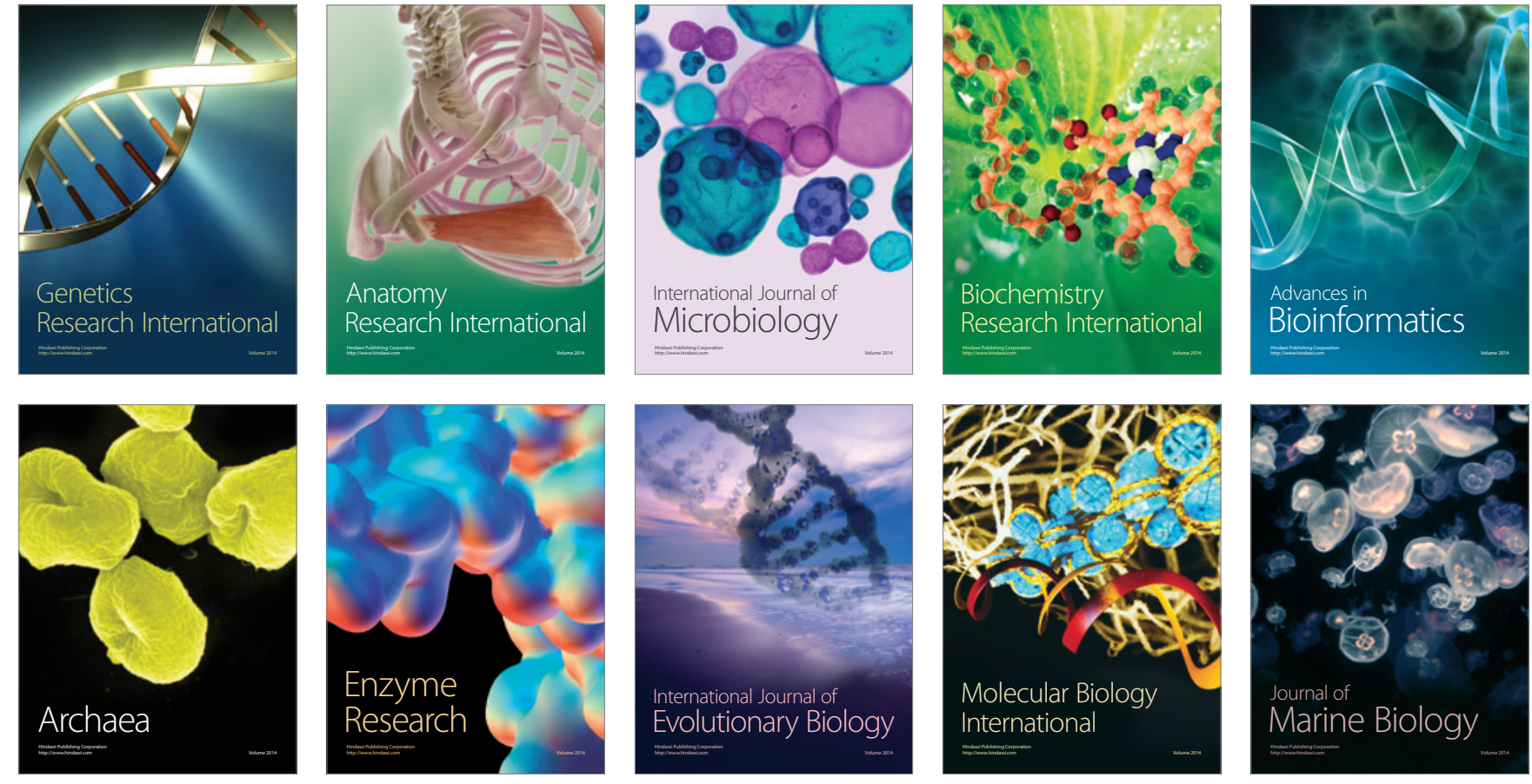